\title{
Draft genome sequence of Annulohypoxylon stygium, Aspergillus mulundensis, Berkeleyomyces basicola (syn. Thielaviopsis basicola), Ceratocystis smalleyi, two Cercospora beticola strains, Coleophoma cylindrospora, Fusarium fracticaudum, Phialophora cf. hyalina, and Morchella septimelata
}

Brenda D. Wingfield ${ }^{1}$, Gerald F. Bills ${ }^{2}$, Yang Dong ${ }^{3,4,5}$, Wenli Huang ${ }^{6}$, Wilma J. Nel ${ }^{1}$, Benedicta S. Swalarsk-Parry ${ }^{1}$, Niloofar Vaghefi' ${ }^{7}$, P. Markus Wilken ${ }^{1}$, Zhiqiang An², Z. Wilhelm de Beer ${ }^{1}$, Lieschen De Vos ${ }^{1}$, Li Chen², Tuan A. Duong ${ }^{1}$, Yun Gao ${ }^{8}$, Almuth Hammerbacher ${ }^{9}$, Julie R. Kikkert ${ }^{10}$, Yan Li ${ }^{2,12}$, Huiying Li ${ }^{11}$, Kuan Li ${ }^{13}$, Qiang Li ${ }^{6}$, Xingzhong Liu ${ }^{13}$, Xiao Ma ${ }^{14}$, Kershney Naidoo $^{1}$, Sarah J. Pethybridge ${ }^{7}$, Jingzu Sun ${ }^{12,13}$, Emma T. Steenkamp ${ }^{1}$, Magriet A. van der Nest ${ }^{1}$, Stephanie van Wyk ${ }^{1}$, Michael J. Wingfield ${ }^{1}$, Chuan Xiong ${ }^{6}$, Qun Yue ${ }^{2,15}$, and Xiaoling Zhang ${ }^{13}$

${ }^{1}$ Department of Biochemistry, Genetics and Microbiology, Forestry and Agricultural Biotechnology Institute (FABI), University of Pretoria, Private Bag x20, Hatfield, Pretoria, 0028, South Africa; corresponding author e-mail: brenda.wingfield@up.ac.za

${ }^{2}$ Texas Therapeutics Institute, The Brown Foundation Institute of Molecular Medicine, University of Texas Health Science Center at Houston, Houston, TX 77054, USA

${ }^{3}$ State Key Laboratory for Conservation and Utilization of Bio-Resources in Yunnan, Yunnan Agricultural University, Kunming, 650201, Yunnan, China

${ }^{4}$ Key Laboratory for Agro-biodiversity and Pest Control of Ministry of Education, Yunnan Agricultural University, Kunming, 650201, Yunnan, China ${ }^{5}$ College of Biological Big Data, Yunnan Agriculture University, Kunming 650504, Yunnan, China

${ }^{6}$ Biotechnology and Nuclear Technology Research Institute, Sichuan Academy of Agricultural Sciences, Chengdu 610065, Sichuan, China

${ }^{7}$ School of Integrative Plant Science, Plant Pathology \& Plant-Microbe Biology Section, Cornell University, Geneva, NY 14456, USA

${ }^{8}$ Nowbio Biotechnology Company, Kunming, 650201, Yunnan, China

${ }^{9}$ Department of Zoology Forestry and Agricultural Biotechnology Institute (FABI), University of Pretoria, Private Bag x20, Hatfield, Pretoria, 0028 ,

South Africa

${ }^{10}$ Cornell Cooperative Extension, Canandaigua, NY 14424, USA

${ }^{11}$ Kunming University of Science and Technology, Kunming 650500, Yunnan, China

${ }^{12}$ Institute of Vegetables and Flowers, Chinese Academy of Agricultural Sciences, Beijing 100081, China

${ }^{13}$ State Key Laboratory of Mycology, Institute of Microbiology, Chinese Academy of Sciences, Beijing 100101, China

${ }^{14}$ Yunnan Plateau Characteristic Agricultural Industry Research Institute, Kunming 650201, Yunnan, China

${ }^{15}$ Biotechnology Research Institute, Chinese Academy of Agricultural Sciences, Beijing 100081, China

\begin{abstract}
Draft genomes of the species Annulohypoxylon stygium, Aspergillus mulundensis, Berkeleyomyces basicola (syn. Thielaviopsis basicola), Ceratocystis smalleyi, two Cercospora beticola strains, Coleophoma cylindrospora, Fusarium fracticaudum, Phialophora cf. hyalina and Morchella septimelata are presented. Both mating types (MAT1-1 and MAT1-2) of Cercospora beticola are included. Two strains of Coleophoma cylindrospora that produce sulfated homotyrosine echinocandin variants, FR209602, FR220897 and FR220899 are presented. The sequencing of Aspergillus mulundensis, Coleophoma cylindrospora and Phialophora cf. hyalina has enabled mapping of the gene clusters encoding the chemical diversity from the echinocandin pathways, providing data that reveals the complexity of secondary metabolism in these different species. Overall these genomes provide a valuable resource for understanding the molecular processes underlying pathogenicity (in some cases), biology and toxin production of these economically important fungi.
\end{abstract}

Key words:

Beta vulgaris

Carya cordiformis

echinocandin gene clusters mulundocandins

Pitch canker

peumocandins 
IMA Genome-F 9A

\section{Draft genome sequence of Annulo- hypoxylon stygium}

\section{INTRODUCTION}

Annulohypoxylon stygium (Xylariales, Ascomycota) is a white-rot fungus commonly found on dead wood (Hsieh et al. 2005). Annulohypoxylon stygium displays an extremely high performance in lignin and carbohydrate degradation. Some species of Annulohypoxylon may be used in the cultivation of Tremella fuciformis, one of the foremost medicinal and culinary fungi of China (Stamets 2000). Tremella fuciformis, the white jelly mushroom, is a symbiotic fungus that does not form an edible basidiome without the presence of a specific host fungus ( $\mathrm{Li}$ et al. 2014). Its preferred host has traditionally been indicated as "Xianghui" in China. Recently, A. stygium was identified to be the main Xianghui species and this has been confirmed experimentally (Deng et al. 2016). Cultivators usually pair cultures of $T$. fuciformis with this species for industrial production and the formation of $T$. fuciformis basidiomes is highly dependent on the presence of the specific host fungus, both in nature and for industrial production.

To date, the symbiotic mechanism of $A$. stygium and T. fuciformis has not been understood yet. The genome sequence of $A$. stygium from this study may provide some useful information to reveal the symbiotic mechanism of $A$. stygium with $T$. fuciformis.

\section{SEQUENCED STRAIN}

China: Sichuan: Tongjiang, N 31 $42^{\prime}$, E 120 $17^{\prime}$, alt. 1523 m, solated from dead wood, 8 Aug. 2015, Qiang Li \& Chuan Xiong (MG137 - dried culture).

\section{NUCLEOTIDE SEQUENCE ACCESSION NUMBER}

The Whole Genome Shotgun project isolate (culture collection number SAAS137) has been deposited at DBJ/EMBL/ GenBank under accession number PYLT00000000. The version described in this paper is version PYLT01000000.

\section{MATERIALS AND METHODS}

Annulohypoxylon stygium MG137 was isolated from dead wood in Tongjiang, Sichuan province, China, and was preserved in the Fungal Culture Collection, Center in Biotechnology and Nuclear Technology Research Institute, Chengdu, Sichuan, China. Genomic DNA was isolated from this isolate and subjected to sequencing on the Genome Analyzer IIx next-generation sequencing platform (Illumina) at the Beijing Genomics Institute (Shenzhen, China). Pairedend libraries with respective insert sizes of 425 bp and 725 bp were used to generate read lengths of 150 bases. The CLC Genomics Workbench v. 6.0.1 (CLCBio, Aarhus, Denmark) was subsequently used to trim reads of poor quality (limit of 0.05 ) as well as terminal nucleotides. The remaining reads were assembled using the SPAdes 3.0.0 with an optimized k-mer value of 103 (Bankevich et al. 2012). Thereafter, scaffolding was completed using SSPACE v. 2.0 (Boetzer et al. 2011) and gaps reduced with the use of GapFiller v. 2.2.1 (Boetzer \& Pirovano 2012). The completeness of the assembly was evaluated using the BUSCO v3 (Simão et al. 2015). Homology-based gene prediction and $a b$ initio prediction were performed to search $A$. stygium gene models. Homologous protein from Laccaria bicolor was used for alignment to the repeat-masked $A$. stygium genome using Exonerate v 2.2.0 (Slater \& Birney, 2005). The filtered alignment results (above $300 \mathrm{bp}$ and $90 \%$ coverage) were built as training models for $a b$ initio gene prediction. The ab initio prediction was conducted using Augustus v. 3.2.3 (Stanke et al. 2008) and GeneMark-ES (Ter-Hovhannisyan et al. 2008) guided by training models from homology-based alignments. All gene prediction results were intergrated into the final gene models by EVidenceModeler (Haas et al. 2008). Carbohydrate-active enzymes (CAZyme), including the repertoire of auxiliary enzymes, were predicted using dbCAN (Yin et al. 2012).

\section{RESULTS AND DISCUSSION}

The genome of $A$. stygium had an estimated size of 47.5 $\mathrm{Mb}$ with an average coverage of $31.26 \times$ (Table 1 ). The N50 size was 598310 bases, and the assembly had a mean GC content of $46 \%$. The total number of scaffold generated was 1854. MAKER predicted a total of 12498 genes with an average length of $1662 \mathrm{bp}$. The average gene density of A. stygium was 263 genes/Mb. A phylogenetic analysis of the genus Annulohypoxylon and the closely related genus Hypoxylon is presented to reflect the position of this genome (Fig. 1.).

The draft genome of $A$. stygium is larger than that of the allied species Xylaria hypoxylon OSC100004 and Hypoxylon sp. Cl-4A (Wu et al. 2017), which are $42.9 \mathrm{Mb}$ and 37.7 $\mathrm{Mb}$, respectively. The genome is closer in size to that of Hypoxylon sp. CO27-5 and Hypoxylon sp. EC38 (Wu et al. 2017), which have genome sizes of $46.6 \mathrm{Mb}$ and $47.7 \mathrm{Mb}$, respectively. Annulohypoxylon stygium also has a similar number of putative genes when compared to Hypoxylon sp. EC38 (12261 predicted gene models) and Hypoxylon sp. CO27-5 (12 256 predicted gene models).

A total 757 CAZymes were identified in the genome of A. stygium, more than that in the closely related Hypoxylon sp. CO27-5 (599 CAZymes) and Hypoxylon sp. Cl-4A (526 CAZymes). The number of CAZymes in A. stygium was much higher than that in Tremella enchepala (265 CAZYmes; Magnuson et al. 2017) and T. mesenterica (206 CAZYmes; Floudas et al. 2012), indicating that $A$. stygium may assist Tremella species in the degradation of lignin and carbohydrates in nature or for industrial production. The genome sequence data of $A$. stygium in this study will provide useful information for understanding the mechanism of the symbiotic interaction between $A$. stygium and T. fuciformis. 


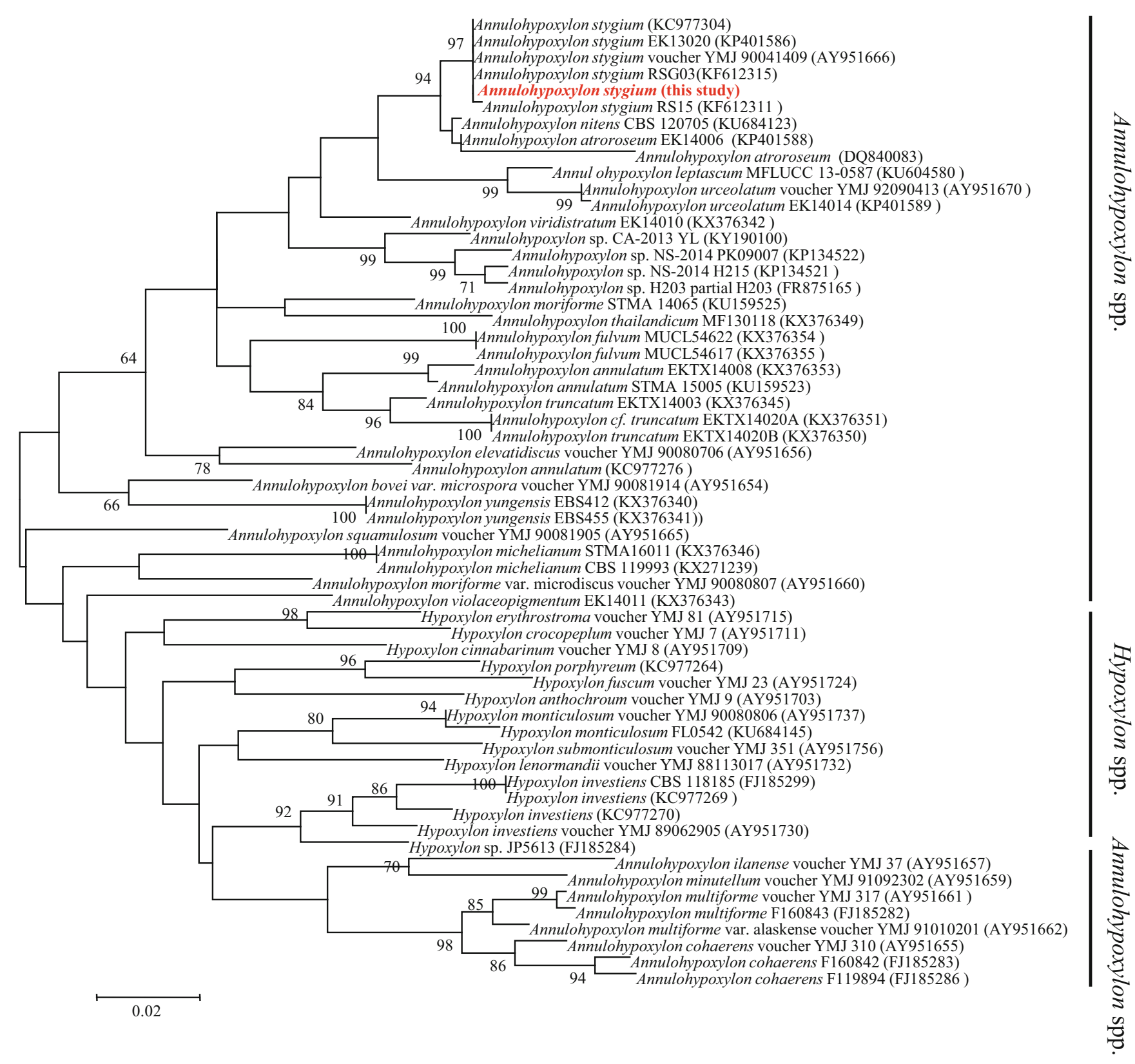

Fig. 1. Maximum Likelihood (ML) phylogenetic analysis of the genus Annulohypoxylon and the closely related genus Hypoxylon using MEGA 6.06 based on partial gene sequences of $\beta$-tubulin. Bootstrap values were calculated using 1000 replicates to assess node support. Annulohypoxylon stygium isolates used for verification was extracted from the assembled genomes. Reference sequences are obtained from the NCBI database with accession number.

Authors: Q. Li, X. Ma, H. Li, C. Xiong, Y. Gao, Y. Dong*, and W. Huang*

*Contact: Yang Dong: loyalyang@163.com; Wenli Huang: wenlih11@126.com 
Table 1. Whole genome DNA sequence assemblies generated in Annulohypoxylon stygium MG137. The genomes of $A$. stygium MG137 were generated using next generation sequencing technology.

\begin{tabular}{|c|c|}
\hline Genome & Annulohypoxylon stygium MG137 \\
\hline Coverage & 31.26 \\
\hline BUSCO & $96.6 \%$ \\
\hline Total sequence length $(\mathrm{Mb})$ & 47.5 \\
\hline Scaffolds & 1854 \\
\hline Scaffold N50 & 598310 \\
\hline GC (\%) & 46 \\
\hline Predicted gene models & 12498 \\
\hline \multicolumn{2}{|l|}{ Predicted CAZYmes } \\
\hline Total CAZYmes & 757 \\
\hline Auxiliary activities & 153 \\
\hline Pectate lyases & 13 \\
\hline Glycosyltransferases & 106 \\
\hline Glycoside hydrolases & 297 \\
\hline Carbohydrate esterases & 125 \\
\hline Carbohydrate binding motifs & 63 \\
\hline \multicolumn{2}{|l|}{ Predicted secondary Metabolite (sM) Clusters } \\
\hline Total SM clusters & 90 \\
\hline Type I polyketide synthetases (PKSs) & 36 \\
\hline Type III PKSs & 1 \\
\hline Nonribosomal peptide synthetases (NRPSs) & 21 \\
\hline Terpene clusters & 10 \\
\hline Hglks & 0 \\
\hline
\end{tabular}

\section{IMA Genome-F 9B}

\section{Draft genome sequence of Aspergil- lus mulundensis, a fungus that pro- duces mulundocandins}

\section{INTRODUCTION}

A strain of Aspergillus ( $\mathrm{Y}-30462=\mathrm{DSMZ} 5745)$ was isolated at Hoechst India, then located in the Mulund district of Mumbai, India, from a soil sample collected in Bangladesh (Mukhopadhyay et al. 1987, Roy et al. 1987). In the original publication, the fungus was described as an unusual variant of $A$. sydowii because of the presence of abundant Hülle cells and was published without a Latin description or type specimen as "A. sydowii var. mulundensis". This strain was subsequently re-examined using multi-gene phylogenetic analysis, chemotaxonomic markers, and morphological data and was determined as representing a novel species within Aspergillus sect. Nidulantes (Bills et al. 2016, Chen et al. 2016).

The primary objective for sequencing the genome of A. mulundensis was the identification of the gene clusterencoding the biosynthesis of the muludocandins (Yue et al. 2015). Mulundocandin and deoxymulundocandin (Fig. 2) are lipohexapeptides and potent antifungal antibiotics of the echinocandin class (Mukhopadhyay et al. 1987, Roy et al. 1987, Mukhopadhyay et al. 1992). Biosynthetically, they are closely related to echinocandin B, but they differ in the substitution of serine instead of threonine in the fifth position of the hexapeptide core and by a 12-methyl myristoyl side chain instead of a lineolyl side chain. Mulundocandin and its deoxymulundocandin have been investigated extensively as potential lead structures for the development of echinocandintype antifungal drugs (Mukhopadhyay et al. 1992, Hawser et al. 1999, Lal et al. 2003, 2004). This draft genome will expand genomic data sets for comparative genomics of species in Aspergillus sect. Nidulantes.

\section{SEQUENCED STRAIN}

Bangladesh: unknown location, isolated from soil at Hoechst (Mumbai, India) (Hoechst Y-30462 = DSMZ $5745=$ CBS $140610=$ IBT 33104).

\section{NUCLEOTIDE SEQUENCE ACCESSION NUMBER}

The Aspergillus mulundensis isolate DSMZ 5745 Whole Genome Shotgun project has been deposited in GenBank under the accession number PVWQ00000000.

\section{MATERIALS AND METHODS}

For methods for DNA extraction, sequencing, and genome assembly and annotation, see Bills et al. (2016). 
Table 2. General features of the genomes of Coleophoma cylindrospora BP6252 and BP5796, Phialophora cf. hyalina BP5553, and Aspergillus mulundensis DSMZ 5745.

\begin{tabular}{lllll}
\hline Features & BP6252 & BP5796 & BP5553 & DSMZ 5745 \\
\hline \hline Assembly size (Mb) & 42.4 & 40.4 & 33.6 & 45 \\
Scaffolds & 77 & 45 & 3.8 & 160 \\
Scaffold N50 (Mb) & 2.3 & 2 & 102 & 2.8 \\
Coverage (fold) & 100 & 100 & 48.2 & 100 \\
G+C content (\%) & 48.7 & 48.5 & 10707 & 43.2 \\
Protein-coding genes & 14177 & 13257 & 324.45 & 11603 \\
Gene density (per Mb) & 337.55 & 331.42 & 3.12 & 257.84 \\
Exons per gene & 3.15 & 3.13 & 19 & 25 \\
PKSs & 15 & 15 & 13 & 19 \\
NRPSs & 8 & 6 & 6 & 1 \\
PKS-NRPS hybrids & 0 & 0 & 2 & 4 \\
DMATSs & 2 & 2 & 4 & 4 \\
Terpene synthases & 1 & 1 & 1 & 0 \\
Chalcone or stilbene synthase gene & 0 & 0 & 48 & 59 \\
Secondary metabolite gene clusters & 30 & 28 & & 25 \\
\hline
\end{tabular}

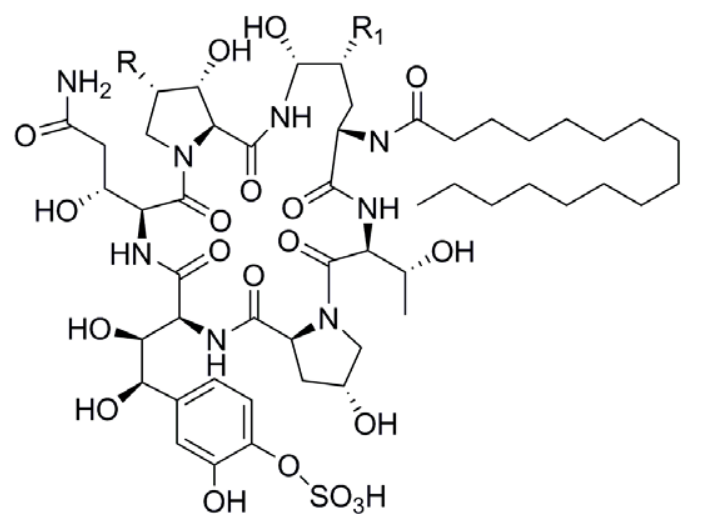

$\mathrm{FR} 220897 \mathrm{R}=\mathrm{CH}_{3}$ FR220899 R=H from Coleophoma cylindrospora BP6252

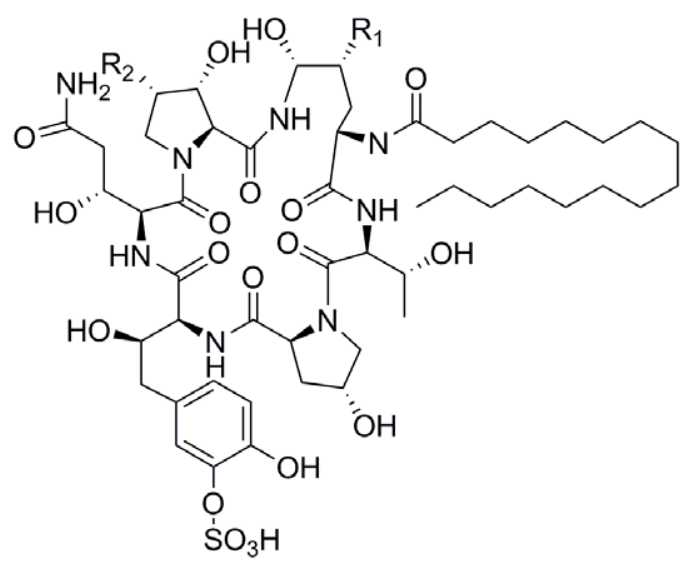

FR209602 R1 $=\mathrm{OH}, \mathrm{R} 2=\mathrm{CH}_{3}$ FR209603 R1 $=\mathrm{OH}, \mathrm{R} 2=\mathrm{H}$ FR209604 R1=H, R2=OH from Coleophoma cylindrospora BP5796

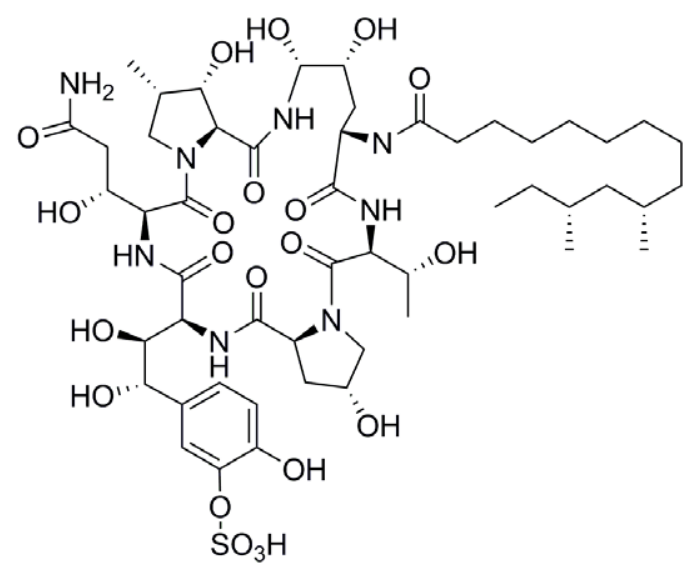

FR190293 from Phialophora cf. hyalina BP5553

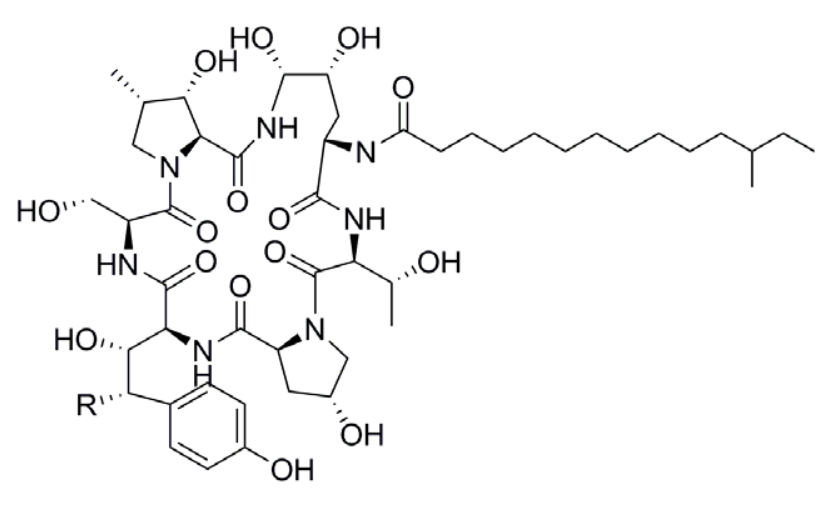

Mulundocandin $\quad \mathrm{R}=\mathrm{OH}$

Deoxymulundocandin $\mathrm{R}=\mathrm{H}$ from Aspergillus mulundensis DSMZ 5745

Fig. 2. Some naturally occurring echinocandins described in the patent literature. 


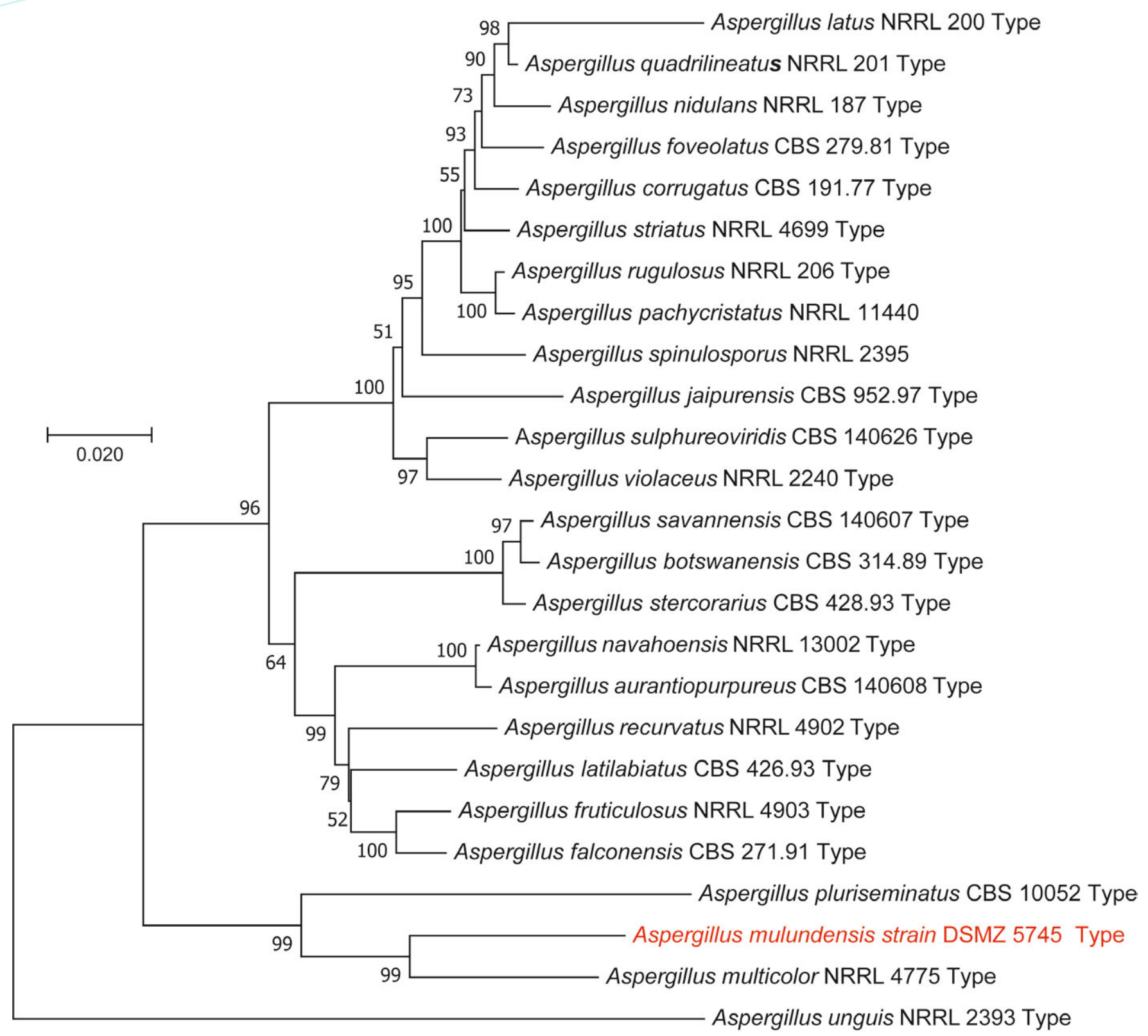

Fig. 3. Maximum Likelihood tree of ex-type and authentic strains of Aspergillus sect. Nidulantes (25 strains) inferred based on an alignment of the concatenated sequences of the ITS-28S rDNA, ribosomal polymerase II, $\beta$-tubulin, and calmodulin genes. Data were resampled from Chen et al. (2016). DMSZ 5745 is labelled in red, and $A$. unguis was positioned as the outgroup. The Maximum Likelihood tree was based on the Tamura-Nei model. The tree with the highest log likelihood (-13 959.85) is shown. Branches are labelled with the percentage of trees in which the associated taxa clustered together. A discrete gamma distribution was used to model evolutionary rate differences among sites (5 categories $(+G$, parameter $=0.2371))$. Branch lengths were measured in the number of substitutions/site. The dataset included 3329 positions. Data were analyzed in MEGA7 (Kumar et al. 2016). "Type" = ex-type cultures.

\section{RESULTS AND DISCUSSION}

The genome of DSMZ 5745 was sequenced to 100 -fold coverage, yielding 160 scaffolds with $\mathrm{N} 50$ of $2.8 \mathrm{Mb}$ (Table 2). The assembled genome size was $45 \mathrm{Mb}$, and a total of 11603 genes were predicted. The GC content of this genome is $43.2 \%$. The genome contains 53 core catalytic genes associated with putative secondary metabolite biosynthetic gene clusters. These clusters include 25 PKSs, 19 NRPSs, one PKS-NRPS hybrids, four dimethylallyl tryptophan synthases, and four terpene synthases. These genes are distributed among 45 putative gene clusters that also include genes encoding tailoring enzymes, regulators, transporters, and other auxiliary genes. In addition to these gene clusters, 14 secondary metabolite gene clusters containing PKS-like or NRPSlike enzyme genes, or other secondary metabolic-related genes were identified by antiSMASH. In addition a gene cluster containing close orthologues of the pneumocandin gene cluster from Glarea lozoyensis (Yue et al. 2015) was recognized, and predicted to be responsible for the biosynthesis of muludocandins. The nuclear-encoded secondary metabolomes of $A$. mulundensis and $A$. nidulans FGSC A4 were compared previously (Bills et al. 2016). A 
phylogenetic tree reflecting the position of this genomes in relation to other Aspergillus species is presented (Fig. 3.)

Authors: Q. Yue, Y. Li, L. Chen, X. Zhang, K. Li, J. Sun, X. Liu, Z. An, and G.F Bills *Contact: billsge@vt.edu

IMA Genome-F 9C

\section{Draft genome sequence of the root pathogen Berkeleyomyces basicola (syn. Thielaviopsis basicola)}

\section{INTRODUCTION}

Berkeleyomyces basicola (Ascomycota: Microascales), previously known as Thielaviopsis basicola (Nel et al. 2017), is an important plant pathogen responsible for root rot of many important agricultural and ornamental plants (Johnson 1916, Stover 1950, Nehl et al. 2004, Pereg 2013). Since its description in the mid-1800s (Berkeley \& Broome 1850), there has been considerable debate surrounding its appropriate taxonomic placement resulting in numerous name changes. The phylogenetic re-evaluation of Ceratocystidaceae by De Beer et al. (2014) raised new questions regarding the appropriate taxonomic placement of the species. Their results suggested that $T$. basicola did not group in Thielaviopsis or any other genus described in the family. Because the authors included only the sequence data of a single isolate in their analyses they concluded that no taxonomic changes could be made without further study. In a recent investigation, Nel et al. (2017) confirmed that $T$. basicola represented a distinct generic lineage in Ceratocystidaceae and introduced the new generic name Berkeleyomyces. In addition, they showed that isolates of Berkeleyomyces represented two cryptic sister species for which they provided the names $B$. basicola and B. rouxiae.

The aim of this study was to generate a high-quality genome sequence for $B$. basicola. This would allow for comparisons to be made with the available genomes of other species in Ceratocystidaceae, including those in the genera Ceratocystis, Huntiella, Davidsoniella, Thielaviopsis, Chalaropsis, Endoconidiophora and the recently described Bretziella (De Beer et al. 2017). Here we report the complete genome sequence of isolate CMW 49352, the designated reference specimen for $B$. basicola logged in CBS (Westerdijk Fungal Biodiversity Institute, Utrecht, The Netherlands), and the culture collection of the Forestry and Agricultural Biotechnology Institute (CMW), University of Pretoria, South Africa.

\section{SEQUENCED STRAIN}

The Netherlands: South Holland, Boskoop, isol ex Betula sp., June 1974. S.G. De Hoog (CMW 49352 = CBS 142796; PREM 62125 = dried culture).

\section{NUCLEOTIDE SEQUENCE ACCESSION NUMBER}

The draft genome sequence of Berkeleyomyces basicola (CMW 49352 = CBS 142796) has been deposited at DDBJ/ ENA/GenBank under the accession number PJAC00000000. The version presented here is PJAC00000000.

\section{MATERIALS AND METHODS}

Genomic DNA was extracted from lyophilized mycelium of Berkeleyomyces basicola isolate CMW 49352 grown in malt yeast broth (2\% Malt extract, $0.5 \%$ yeast extract; Biolab, Midrand, South Africa) using the method described by Duong et al. (2013). A paired-end library was prepared (350 bp average insert sizes) and sequenced using the Illumina HiSeqX Platform. A mate-pair library was prepared (10 Kb average insert size) and sequenced using the Illumina HiSeq2500 platform. Long reads were also generated using one cell of the Single-molecule real time (SMRT or PacBio) sequencing platform (Pacific BioScience). All sequencing was conducted at Macrogen (Seoul, Korea). Quality and adapter trimming of pair-end and mate-pair reads was carried out using Trimmomatic v. 0.36 (Bolger et al. 2014). De novo assembly of the genome was carried out using SPAdes v. 3.9 (Bankevich et al. 2012) using all pair-end, mate-pair and PacBio data. Contigs smaller than $500 \mathrm{bp}$ were removed from the dataset. Initial scaffolding was done using SSPACE-standard v. 3.0 (Boetzer et al. 2011) with the paired-end and mate-pair reads. A second round of scaffolding was done using SSPACELongread with the PacBio reads. Assembly gaps were filled using GapFiller v. 1.10 (Boetzer \& Pirovano 2012) with the paired-end and mate-pair reads, and using PBJelly (English et al. 2012) with PacBio reads. Final genome polishing was done using Pilon (Walker et al. 2014). Genome completeness was assessed with the Benchmarking Universal Single-Copy Orthologs (BUSCO v. 1.1b1) tool using the Ascomycota dataset (Simão et al. 2015). The number of protein coding genes was determined using Augustus v. 3.3.2 (Stanke et al. 2004) using pre-optimised species models for Fusarium graminearum.

\section{RESULTS AND DISCUSSION}

The paired-end, mate-pair, and PacBio sequencing yielded 431141384,60673400 and 42422 reads, respectively. Final assembly consisted of 81 contigs, with the largest around 3.8 $\mathrm{Mb}$ and an N50 of $1.2 \mathrm{Mb}$. The estimated size of the genome is around $25.1 \mathrm{Mb}$ with a GC content of $52 \%$. This estimated size is similar to that of other species in Ceratocystidaceae, which range between 25.4 Mb for Huntiella moniliformis and 33.6 Mb for Davidsoniella virescens (Wilken et al. 2013, Van der Nest et al. 2014a, b, Wingfield et al. 2015a, b, 2016a, b). The phylogenetic position of Berkeleyomyces basicola is presented in Fig. 4 .

BUSCO analysis predicted an assembly completeness of $97.4 \%$. The assembly contained 1280 complete singlecopy BUSCOs, one complete and duplicated BUSCOs, 10 fragmented BUSCOs and 24 missing BUSCOs out of a total 1315 BUSCO groups searched. AUGUSTUS annotation predicted 10074 putative coding regions, corresponding to 


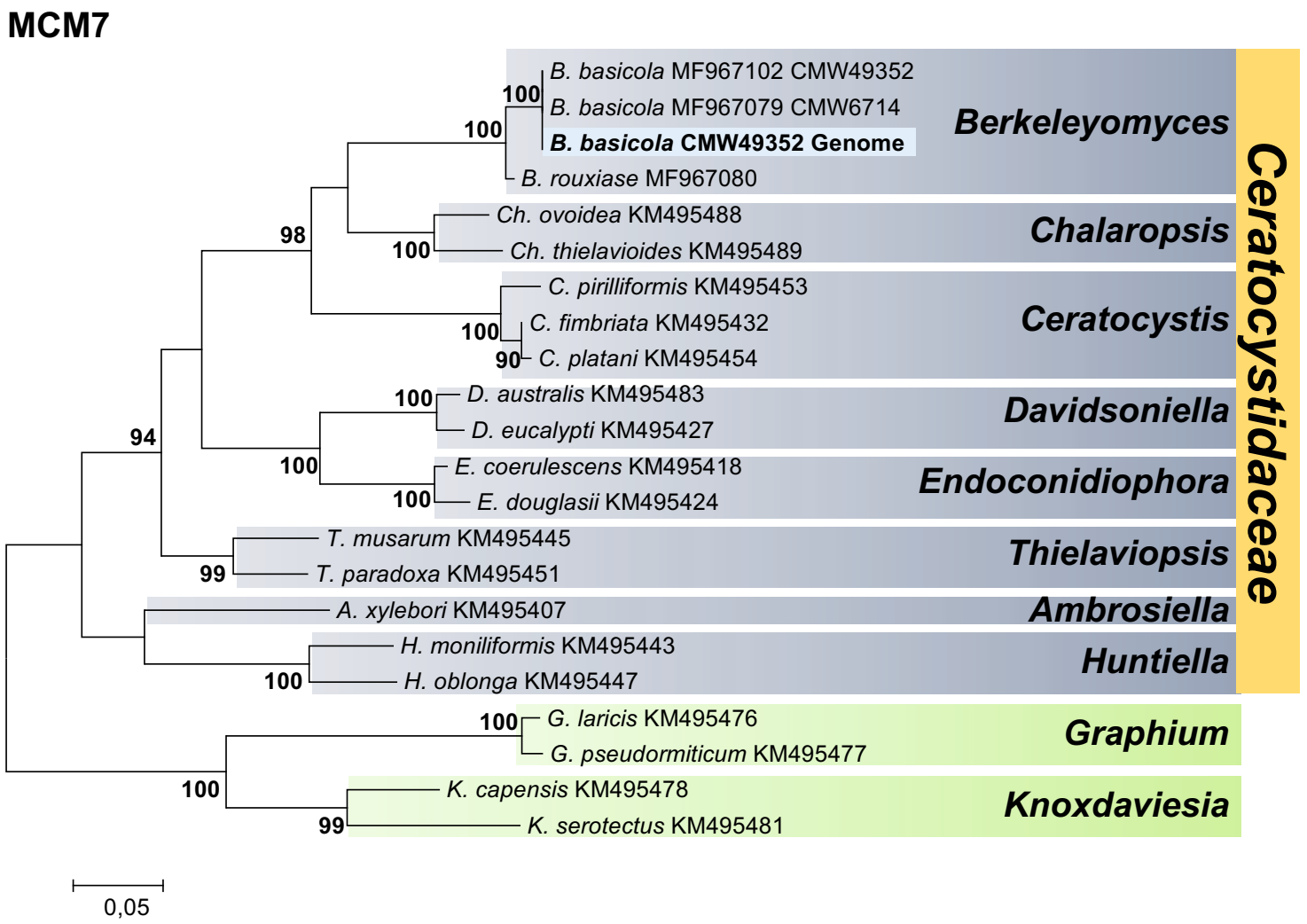

Fig. 4. Maximum Likelihood (ML) phylogram derived from the analyses of the partial MCM7 gene sequences for species in Ceratocystidaceae. CLCbio Genomics Workbench v. 9.5 (CLCbio, QIAGEN, Aarthus, Denmark) was used to screen the genome of $B$. basicola isolate CMW 49352 to identify and extract the MCM7 gene using an available reference sequence for the gene from B. basicola (Accession: MF967102). A dataset was prepared based on the phylogenies of Nel et al. (2017) and sequences were downloaded from NCBI GenBank. DNA sequence alignments of the dataset were done using the online version of MAFFT v. 7 (Katoh \& Standley, 2013). The ML analyses were performed in MEGA v. 6.06 (Tamura et al. 2013) using the GTR model. Values shown at nodes are confidence values $>75 \%$. The sequence from the $B$. basicola genome is indicated in bold.

around 401 ORFs/Mb. The availability of the genome for $B$. basicola will make possible genome comparisons with other species in Ceratocystidaceae and facilitate investigations into factors involved in pathogenicity, ecology, mating, and evolution of this important plant pathogen.

Authors: W.J. Nel, T.A. Duong, A. Hammerbacher, B.D. Wingfield, M.J. Wingfield, and Z.W. De Beer ${ }^{*}$ Contact: janine.nel@fabi.up.ac.za

\section{IMA Genome-F 9D}

\section{Draft nuclear genome assembly for Ceratocystis smalleyi}

\section{INTRODUCTION}

The genus Ceratocystis as defined by De Beer et al. (2014) is a diverse assemblage of species that are best known as pathogens of angiosperm trees and commercially grown root crops (De Beer et al. 2014, Li et al. 2016, Seifert et al. 2013, Van Wyk et al. 2012). Among these, C. fimbriata s. lat. is arguably the best-known pathogen, and has been associated with diseases of sweet potato (Halsted \& Fairchild 1891), taro (Huang et al. 2008), pomegranate (Somasekhara 1999) and kiwifruit (Piveta et al. 2016). The related C. manginecans causes disease on mango and Acacia mangium trees in Oman and Pakistan (Al-Subhi et al. 2006, Al Adawi et al. 2013), while C. eucalypticola is responsible for mortality on commercially planted eucalypt trees in South Africa (Van Wyk et al. 2012). These fungi all share a very similar morphology, making their species boundaries difficult to determine (Fourie et al. 2014, Harrington et al. 2014). In contrast, several other species in the genus are clearly defined, with universally accepted species status (Engelbrecht \& Harrington 2005). These include $C$. albifundus (a pathogen of commercially propagated Acacia mearnsii and Protea cynaroides in South Africa; Lee et al. 2016), C. cacaofunesta (causing cacao wilt in the Caribbean and Central and South America; Engelbrecht et al. 2007), and C. smalleyi (agent of hickory decline in the USA; Johnson et al. 2005).

Ceratocystis smalleyi was first isolated from a hickory tree (Carya sp.) that had been infested by the hickory bark beetle Scolytus quadrispinosus (Johnson et al. 2005). In 2005 , C. smalleyi was formally named and described after additional isolates were collected from Carya trees that had been attacked by the hickory bark beetle across parts of the eastern US (Johnson et al. 2005). The authors subsequently linked C. smalleyi with the decline of hickory through a possible 
association with the bark beetle $S$. quadrispinosus (Johnson et al. 2005). Later studies have confirmed C. smalleyi as a pathogen on Carya species (Park et al. 2010, 2013), and established the close association between the fungus and the bark-beetle (Juzwik et al. 2010). This makes C. smalleyi the only known Ceratocystis species to be associated with a bark-beetle. In other Ceratocystis species, the production of volatiles is linked to attracting insects for dispersal (Van Wyk et al. 2009, 2012). The specific association between C. smalleyi and the vector $S$. quadrispinosus would eliminate the need for producing volatile attractants, and could explain the inability of this species to produce the fruity odours characteristic of other Ceratocystis species (Harrington 2009; Johnson et al. 2005).

In this study, we aimed to produce a draft genome assembly for $C$. smalleyi. This assembly would be the seventh Ceratocystis species for which a genome sequence is published, and adds to the valuable genomic resource available for members of Ceratocystidaceae (Molano et al. 2018, Van der Nest et al. 2014a, b, 2015, Vanderpool et al. 2017, Wilken et al. 2013, 2018, Wingfield et al. 2015a, b, 2016a, b). Furthermore, the availability of a genome assembly will afford the opportunity in future to investigate aspects of the unique biology of $C$. smalleyi.

\section{SEQUENCED STRAIN}

USA: Wisconsin: Hickory Ridge, isol. Carya cordiformis. Oct. 1993, G. Smalley (CMW 14800, CBS 114724, BPI 843722 dried culture).

\section{NUCLEOTIDE SEQUENCE ACCESSION NUMBER}

This Whole Genome Shotgun project for Ceratocystis smalleyi isolate CMW 14800 has been deposited at DDBJ/ ENA/GenBank under accession NETT00000000. The version described in this paper is version NETT01000000.

\section{MATERIALS AND METHODS}

Ceratocystis smalleyi isolate CMW 14800 was obtained from the culture collection of the Forestry and Agricultural Biotechnology Institute (FABI) and grown on $2 \%$ malt extract agar (MEA: $2 \% \mathrm{w} / \mathrm{v}$, Biolab, South Africa) at $25^{\circ} \mathrm{C}$. A $14 \mathrm{~d}$ old culture was used to isolate genomic DNA using a previously described phenol-chloroform protocol (Roux et al. 2004). The isolated DNA was submitted for sequencing on an Illumina Genomics Analyzer IIx at the UC Davis Genome Centre (University of California, Davis). For sequencing, paired-end libraries of $350 \mathrm{bp}$ and $600 \mathrm{bp}$ insert sizes were prepared and sequenced following the protocol provided by Illumina (www. illumina.com). The raw sequencing reads were imported into CLC Genomics Workbench v. 7.5.1 (CLCBio. Aarhus), and default settings were used to both trim the reads for quality and to produce a de novo genome assembly using the trimmed reads. Scaffolds were generated from the assembly using
SSPACE v. 2.0 (Boetzer et al. 2011), while GapFiller v. 2.2.1 (Boetzer \& Pirovano 2012) was used to fill any gaps created during scaffolding. Sequencing coverage was estimated by mapping the trimmed sequencing reads to the contigs, while an estimate of the number of putative open reading frames (ORFs) were obtained through de novo gene prediction using the web-based version of AUGUSTUS and gene models from Fusarium graminearum (Keller et al. 2011). The Benchmarking Universal Single-Copy Orthologs (BUSCO v. 1.22) tool was used in combination with the fungal data set to provide a quantitative measure of the level of genome completeness (Simão et al. 2015). The 60S, LSU and MCM7 gene regions were extracted from the genome and, together with these regions from the recently sequenced species $C$. cacaofunesta (Molano et al. 2018), T. punctulata isolate CMW1032 (Wilken et al. 2018), H. savannae (Van der Nest et al. 2015) and $A$. xylebori (Vanderpool et al. 2017) were added to the Ceratocystidaceae dataset used for phylogenetic analysis by Wingfield et al. (2017). The resulting datasets were aligned using MUSCLE (Edgar 2004), concatenated, and used to construct a Maximum Likelihood phylogeny using PhyML 3.1 (Guindon et al. 2010) based on model parameters estimated with jModelTest 2.1.10 (Darriba et al. 2012).

\section{RESULTS AND DISCUSSION}

The 27311342 bp Ceratocystis smalleyi genome was present in 2261 contigs, of which 1242 contigs were larger than 500 bp. The draft assembly yielded a genome with a G/C content of $50.6 \%$, an average coverage of $84 x$ and 6682 predicted open reading frames at an average gene density of 245 ORFs/ $\mathrm{Mb}$. BUSCO analysis indicated a genome completeness of $97 \%$ with 1394 of the 1438 searched orthologs present in the genome being complete. In total 1330 ORFs occurred as single copies while 64 were duplicates. Of the remaining searched homologs, 37 were fragmented while the remaining seven were missing from the genome assembly.

The genome of C. smalleyi was comparable in size and gene content to that of other Ceratocystis species (Wingfield et al. 2015b, 2016a, b). At $27.3 \mathrm{Mb}$, the C. smalleyi genome is slightly larger than that of the related species $C$. harringtonii (genome size of $26 \mathrm{Mb}$; Wingfield et al. 2016b), but smaller than the genome of $C$. manginecans (31.7 Mb; Van der Nest et al. 2014b). Gene densities for published Ceratocystis genomes range from 204-257 ORF/Mb (Wingfield et al. 2015b, 2016a, b), and the C. smalleyi gene density falls within this range. In contrast, the $50.6 \% \mathrm{G} / \mathrm{C}$ content of the $C$. smalleyi genome is unusually high, with all other Ceratocystis species showing G/C contents below $49 \%$ (Wingfield et al. 2015b, 2016a, b).

The availability of multiple Ceratocystis genomes (Fig. 5 ) provides the opportunity to study the genetic aspects that underlie ecological and life-style differences between members of this genus. Understanding these differences will also be crucial in explaining at least some of the variations in gene content, genome size, and G/C content evident among these genomes. Currently, the published Ceratocystis genomes make up the bulk of the Ceratocystidaceae 


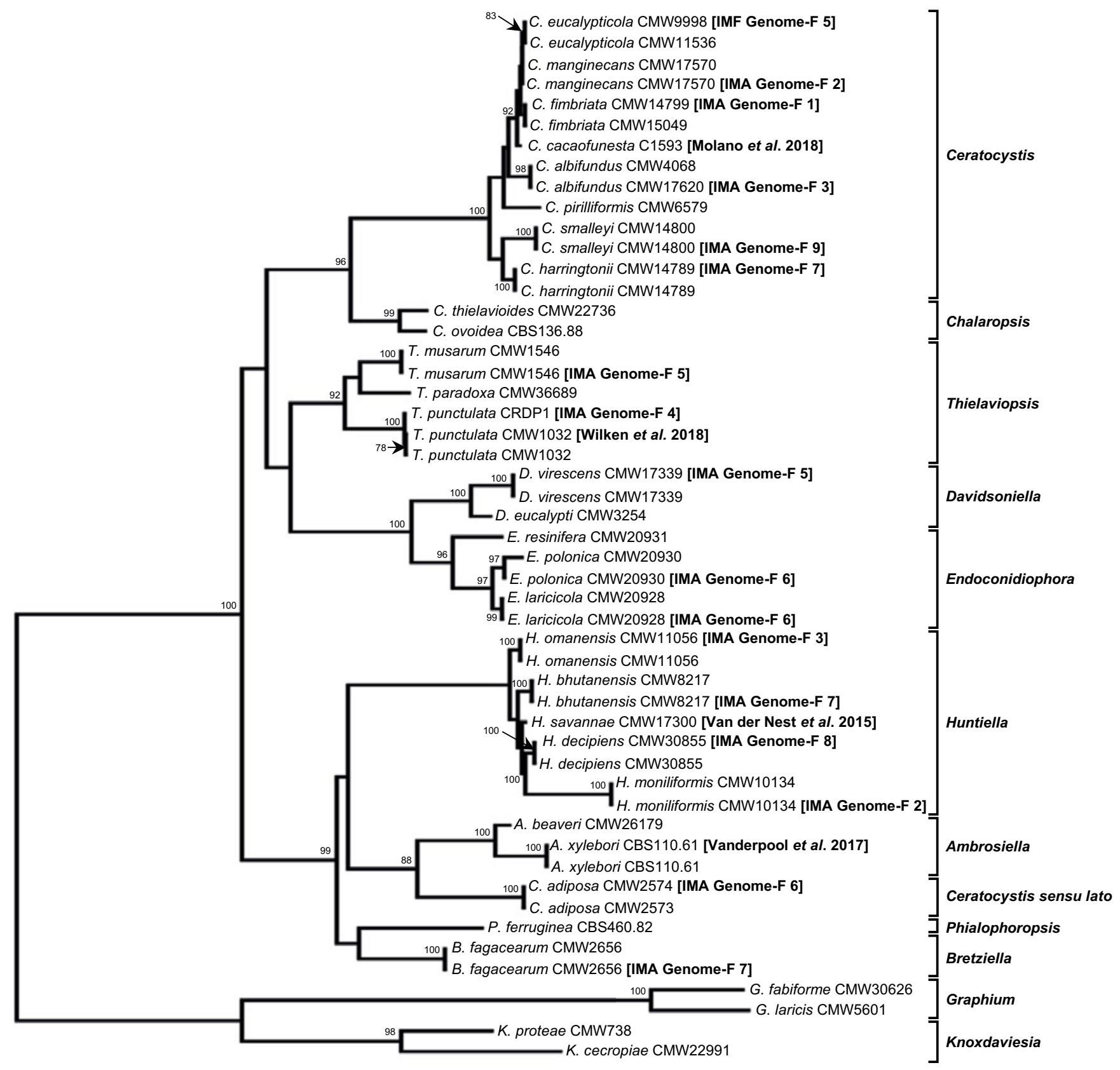

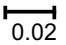

Fig. 5. A Maximum Likelihood phylogeny showing Ceratocystidaceae isolates for which published whole-genome sequences are available, including that of $C$. smalleyi discussed here. The 60S, LSU, and MCM7 gene regions were used, and was either extracted from the assembled genomes or were obtained from the study of Wingfield et al. (2017). Phylogeny constructed using the $T r N+I+G$ model with confidence values based on 1000 bootstrap replicates. Only bootstrap values $\geq 75$ are shown.

genome resource with published genomes available for seven species (Fig. 5; Molano et al. 2018, Van der Nest et al. 2014a, b, Wilken et al. 2013, Wingfield et al. 2015b, 2016b). In addition, published genome sequences are available for five Huntiella species (Van der Nest et al. 2014a, b, 2015, Wingfield et al. 2016b, 2017), two Endoconidiophora species (Wingfield et al. 2016a), three isolates representing two Thielaviopsis species (Wilken et al. 2018, Wingfield et al. 2015a; Wingfield et al. 2015b), one Davidsoniella species (Wingfield et al. 2015b), one Bretziella species (previously Ceratocystis fagacearum; De Beer et al. 2017, Wingfield et al. 2016b), one Ambrosiella species (Vanderpool et al. 2017) as well as for $C$. adiposa (Wingfield et al. 2016a). This brings the number of published Ceratocystidaceae genomes to 21 , with the genome assemblies of several others publicly available (www.ncbi.nlm.nih.gov/assembly/?term=ceratocyst idaceae). Such a vast genomic resource will prove valuable to future studies on Ceratocystidaceae, a family that include fungal species with diverse life-styles and hosts.

Authors: P.M. Wilken*, M.A. van der Nest, E.T. Steenkamp, K. Naidoo, M.J. Wingfield, and B.D. Wingfield

* Contact: Markus.Wilken@fabi.up.ac.za 


\section{Draft genome sequences of two Cercospora beticola strains from table beet}

\section{INTRODUCTION}

The genus Cercospora (Mycosphaerellaceae) includes several economically important plant pathogens causing leaf and fruit spots on a range of agricultural crops worldwide (Groenewald et al. 2013). Cercospora species are known to produce cercosporin, a photo-activated toxin that contributes to pathogenicity on a broad range of crops (Daub et al. 2000). Cercospora beticola is the cause of Cercospora leaf spot (CLS) on sugar and table beet (Beta vulgaris ssp. vulgaris), and Swiss chard (Beta vulgaris ssp. cicla) worldwide (Franc 2010). In New York, CLS is the most important disease affecting foliar health of table beet. Symptoms include leaf spots and necrotic lesions with red to purple margins, which coalesce as the disease progresses, and can result in complete defoliation (Pethybridge et al. 2017). In broadacre production systems, maintenance of foliar health is important to enable mechanized harvest. For fresh market sales, the presence of CLS lesions on the leaves may result in rejection (Pethybridge et al. 2017).

The control of CLS in table beet is dependent on fungicides (Pethybridge et al. 2017). However, resistance to single-site mode of action fungicides threatens the durability of CLS control. Recent studies reported a high frequency of isolates with resistance to quinone outside inhibitor fungicides in New York (Vaghefi et al. 2016). Moreover, succinate dehydrogenase inhibitor fungicides, which are known to be effective in controlling CLS on sugar beet, failed to provide efficacious control on table beet (Pethybridge et al. 2017), and a few isolates with reduced sensitivity to demethylation inhibitors have been detected (Pethybridge, unpubl.). Identifying genomic regions associated with sensitivity to fungicides will enable rapid screening of $C$. beticola populations. Enhanced genomic information for this pathogen will also facilitate studies into the mechanisms of pathogenicity. De novo genome assembly of two C. beticola strains from table beet are presented here, and made publically available to facilitate genetic studies of this globally important plant pathogen.

\section{SEQUENCED STRAINS}

USA: New York: western New York, Batavia, from Beta vulgaris ssp. vulgaris (table beet), 2014, F.S. Hay (Tb14-085 = ICMP 21692); ibid. (Tb14-047 = ICMP 21690).

\section{NUCLEOTIDE SEQUENCE ACCESSION NUMBER}

The Whole Genome Shotgun projects have been deposited at DDBJ/EMBL/GenBank under the accessions PDUH00000000 and PDUI00000000.
Two C. beticola isolates belonging to opposite mating-types (ICMP 21690 [MAT-2] and ICMP 21692 [MAT-1]), collected from table beet in New York, were selected for whole genome sequencing. The identity of the strains as $C$. beticola was confirmed through multi-locus sequence typing of five loci; ITS, actin, calmodulin, histone $\mathrm{H} 3$ and translation elongation factor 1-a (Fig. 6). Fungal strains were cultured in clarified V8 broth (10\% (v/v) clarified V8 juice (Campbell's Soup, USA), $0.5 \%(\mathrm{w} / \mathrm{v}) \mathrm{CaCO}_{3}$ ). Seven-day-old mycelia were harvested, and genomic DNA was extracted as described in Vaghefi et al. (2016). The extracted DNA samples were quantified using a Qubit fluorometer (Invitrogen, NY).

A total of 5.6 and $5.0 \mu \mathrm{g}$ genomic DNA of ICMP 21692 and ICMP 21690 were used to prepare PCR-free libraries with average insert of $\sim 550 \mathrm{bp}$, using the Illumina paired-end ( $2 \times 300 \mathrm{bp})$ MiSeq platform at the Cornell University Institute of Biotechnology Genomics Facility (Ithaca, NY). PCR-free libraries were constructed using Illumina's TruSeq Nano DNA LT Sample Preparation kits, according to the manufacturer's protocol. This yielded 4607564 and 4798846 paired-end reads, totalling 2.7 and $2.9 \mathrm{~Gb}$ data for ICMP 21692 and ICMP 21690 , respectively. Quality control of the sequences was conducted using FastQC v.0.11.2 (http://www.bioinformatics. bbsrc.ac.uk/projects/fastqc) in the GALAXY portal (Afgan et al. 2016). The Kmer counting software Jellyfish v.2.2.3 (Marçais \& Kingsford 2011) was used to estimate the genome size.

De novo genome assembly was conducted using DISCOVAR de novo v.52488; an assembler designed for de novo assembly of long Illumina paired-end reads from single PCR-free libraries (Weisenfeld et al. 2014). The completeness of the final assemblies was assessed using Benchmarking Universal Single-Copy Orthologs (BUSCO) v.1.2 (Simão et al. 2015). Gene prediction was conducted in the genome annotation pipeline Maker v.2.31.9 (Cantarel et al. 2008), using contigs at least 500 bp in length only for ICMP 21692. A preliminary annotation used the $a b$ initio gene prediction program SNAP (Korf 2004). The resulting annotation was used to produce a hidden-markov-model (HMM) profile for C. beticola, which was further refined with a second stage of SNAP training. The refined HMM file was used for the final annotation (Cantarel et al. 2008).

\section{RESULTS AND DISCUSSION}

The Illumina paired-end ( $2 \times 300 \mathrm{bp})$ sequencing of $C$. beticola isolates ICMP 21692 and ICMP 21690, resulted in 4607564 and 4798846 reads for each strain, respectively, with mean base quality of 28.5 and 28.7. The estimated genome size of C. beticola was $\sim 37 \mathrm{Mb}$, based on an approximated genome coverage for both strains of at least $74 \times$. The draft genome of ICMP 21692 had a total assembly size of $\sim 35.03 \mathrm{Mbp}$ (for $1 \mathrm{~kb}+$ scaffolds), a scaffold N50 value of $1023488 \mathrm{bp}$, and maximum contig size of $3283856 \mathrm{bp}$. The draft genome of ICMP 21690 had a total assembly size of $\sim 34.5 \mathrm{Mbp}$ (for 1 $\mathrm{kb}+$ scaffolds), and a scaffold N50 value of $654439 \mathrm{bp}$, and maximum contig size of $2437838 \mathrm{bp}$. Both assemblies were 


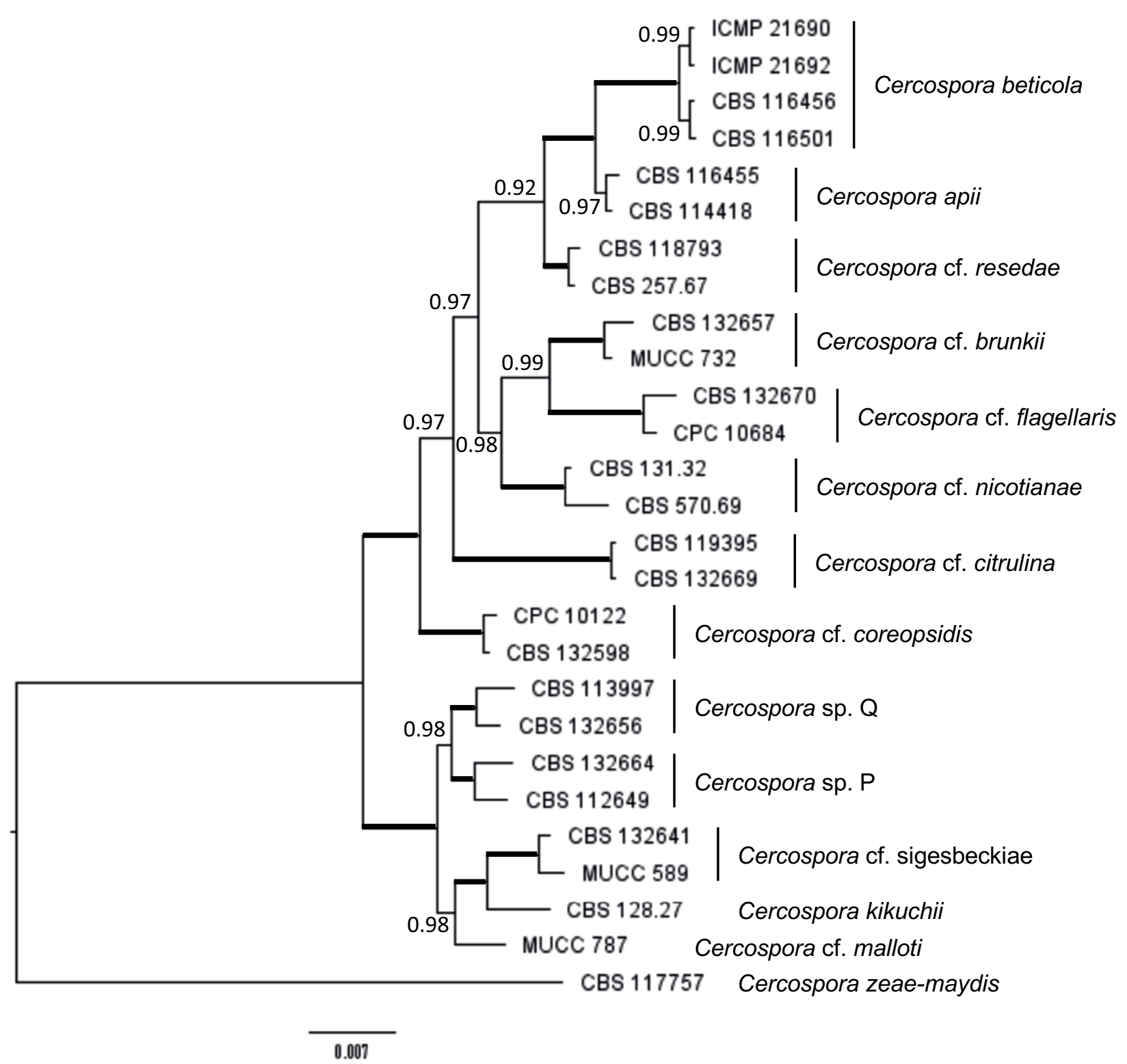

Fig. 6. Identity verification of Cercospora beticola isolates sequenced in this study. The phylogeny was constructed by Bayesian inference based on the sequences of five loci; ITS, act, $c m d$, his and tef1- $\alpha$. Sequence alignments were produced using MAFFT v. 7 (Katoh \& Standley 2013) (MrBayes v. 3.1.2; Ronquist \& Huelsenbeck, 2003). Branches with posterior probability of 1.00 are thickened. The tree was rooted to C. zeaemaydis (CBS 117757).

$97 \%$ complete based on the content of BUSCO. All contigs with a length of $\geq 200 \mathrm{bp}$ were submitted to the genome database of NCBI. Ab initio gene prediction for ICMP 21692 using trained SNAP identified 12834 Open Reading Frames (ORFs).

The estimated genome size of $C$. beticola $(37 \mathrm{Mb})$ is comparable to that of multiple Cercospora species, including C. canescens ( $34 \mathrm{Mb}$; Chand et al. 2015), C. cf. sigesbeckiae ( 35 Mb; Albu et al. 2017), and C. zeina ( 37 Mb; Wingfield et al. 2017). The draft genome of ICMP 21692 has already provided the foundation for global population genetics studies of $C$. beticola using microsatellite markers and GenotypingBy-Sequencing (Vaghefi et al. 2017a, b). Current studies are focused on identification and characterisation of the genes responsible for sensitivity to fungicides. Availability of genomic data will provide a powerful tool for characterising the genes involved in pathogenicity.

Authors: N. Vaghefi ${ }^{\star}$, J.R Kikkert, and S.J. Pethybridge ${ }^{*}$ Contact: Niloofar.Vaghefi@usq.edu.au 


\section{SEQUENCED STRAIN}

\section{Draft genome sequence of Coleophoma cylindrospora BP6252, the fungus used to produce sulfated echinocandins FR220897 and FR220899}

\section{INTRODUCTION}

Researchers at Fujisawa Pharmaceutical (now Astellas Pharma) isolated strain BP6252 (No. 14573) from an unidentified decaying leaf from Tsushima Island, Japan and identified it as Coelophoma empetri. They fermented the strain to produce two water-soluble echinocandin analogues FR220897 and FR220899 (WF14573A and WF14573B) (Hori et al. 2004, Kanasaki et al. 2006) (Fig. 2). FR220897 and FR220899 are isomers of FR901379 which is used for semisynthesis of micafungin. FR901379 is produced by a different strain of $C$. empetri F-11899 (Iwamoto et al. $1994 a, b)$. Differential antifungal activity of these isomers was critical to understanding the effects of the position of the homotyrosine sulfate residue on the antifungal activity (Hino et al, 2001, Kanasaki et al. 2006). Like other echinocandins, the metabolites strongly inhibited $\beta-1,3$-glucan synthase and exhibited potent in vitro activity against Candida albicans and Aspergillus fumigatus, and FR220897 was effective in mouse candidiasis models. The discovery of these echinocandin variants was significant because sulfation of the homotyrosine residue overcomes the inherent poor water-solubility that had previously impeded development of echinocandin-type of antibiotics, including echinocandin B, aculeacins, and the pneumocandins.

Coleophoma cylindrospora is a widespread endophyte and leaf saprobe and can be a weak pathogen of leaves and fruits of many woody plants (Sutton 1980, Wu et al. 1996, Polashock et al. 2009, Crous \& Groenewald 2016). The phylogenetic affinity of the strain producing FR220897 and FR220899 was established with multiple phylogenetic marker sequences and was found to be conspecific with other strains of C. empetri (Yue et al. 2015) (Fig. 7). Subsequently, during a revision of the polyphyletic genus Coleophoma, C. empetri was found to be phylogenetically indistinct from the similar C. cylindrospora and was considered to be a synonym of the latter (Crous \& Groenewald 2016).

The primary objective behind the sequencing the genome of $C$. cylindrospora was the identification of the gene clusterencoding the biosynthesis of FR220897 and FR220899 (Yue et al. 2015). The genome sequence will be essential for identifying the mechanism of the regiospecific sulfation reaction. The draft genome also has revealed that the strain harbours an auxiliary copy of $\beta-1,3$-glucan synthase that may function as an echinocandin resistance gene (Yue et al. 2018). This draft genome will expand genomic data sets for comparative genomics of species in Leotiomycetes, Dermataceae, and endophytic fungi in general.
Japan: Tsushima Island: Nagasaki Prefecture, isolated from decaying leaf, [no further information] (NBRC-NITE BP6252, Fujisawa No. 14573).

\section{NUCLEOTIDE SEQUENCE ACCESSION NUMBER}

The C. cylindrospora isolate BP6252 Whole Genome Shotgun project has been deposited in GenBank under the accession number PDLM00000000.

\section{MATERIALS AND METHODS}

Lyophilized mycelia harvested from liquid cultures were ground in liquid nitrogen and genomic DNA was isolated by using the CTAB protocol (http://1000.fungalgenomes.org/home/ wp-content/uploads/2013/02/genomicDNAProtocol-AK0511. pdf). A $180 \mathrm{bp}$ insert library and a $5 \mathrm{~kb}$ mate-pair library were constructed for Illumina sequencing and were sequenced on an Illumina Hiseq2000 V4 sequencing platform (Yue et al. 2015). The Illumina sequencing reads were assembled using Velvet 1.2 (Zerbino \& Birney 2008). Ab initio gene predictions from the genome assembly were made with Augustus (Stanke et al. 2004). Predicted genes were annotated by BLAST searches against UniProt databases (http://www.uniprot.org/). Polyketide synthases (PKSs), non-ribosomal peptide synthetases (NRPSs), dimethylallyl tryptophan synthases and related biosynthetic gene clusters were predicted by antiSMASH ver. 3.0 and manual annotation (Weber et al. 2015).

\section{RESULTS AND DISCUSSION}

The genome of BP6252 was sequenced to 100 -fold coverage, yielding 77 scaffolds with N50 of 2.3 megabases (Mb). The assembled genome size was $42.4 \mathrm{Mb}$, and a total of 14,177 genes were predicted. The GC content of this genome is 48.7 $\%$. The genome contains 26 core catalytic genes associated with putative secondary metabolite biosynthetic gene clusters. These clusters include 15 PKSs, eight NRPSs, two dimethylallyl tryptophan synthases, and one terpene synthase. These genes are distributed among 21 putative gene clusters that also include genes encoding tailoring enzymes, regulators, transporters, and other auxiliary genes. In addition to these gene clusters, nine secondary metabolite gene clusters containing PKS-like or NRPS-like enzyme genes, or other secondary metabolic-related genes were identified by antiSMASH. In addition a gene cluster containing close orthologues of the pneumocandin gene cluster from Glarea lozoyensis (Yue et al. 2015) was recognized and predicted to be responsible for the biosynthesis of FR220897 and FR220899.

Authors: Q. Yue, Y. Li, L. Chen, X. Zhang, K. Li, J. Sun, $X$. Liu, Z. An, and G.F Bills* *Contact: billsge@vt.edu 


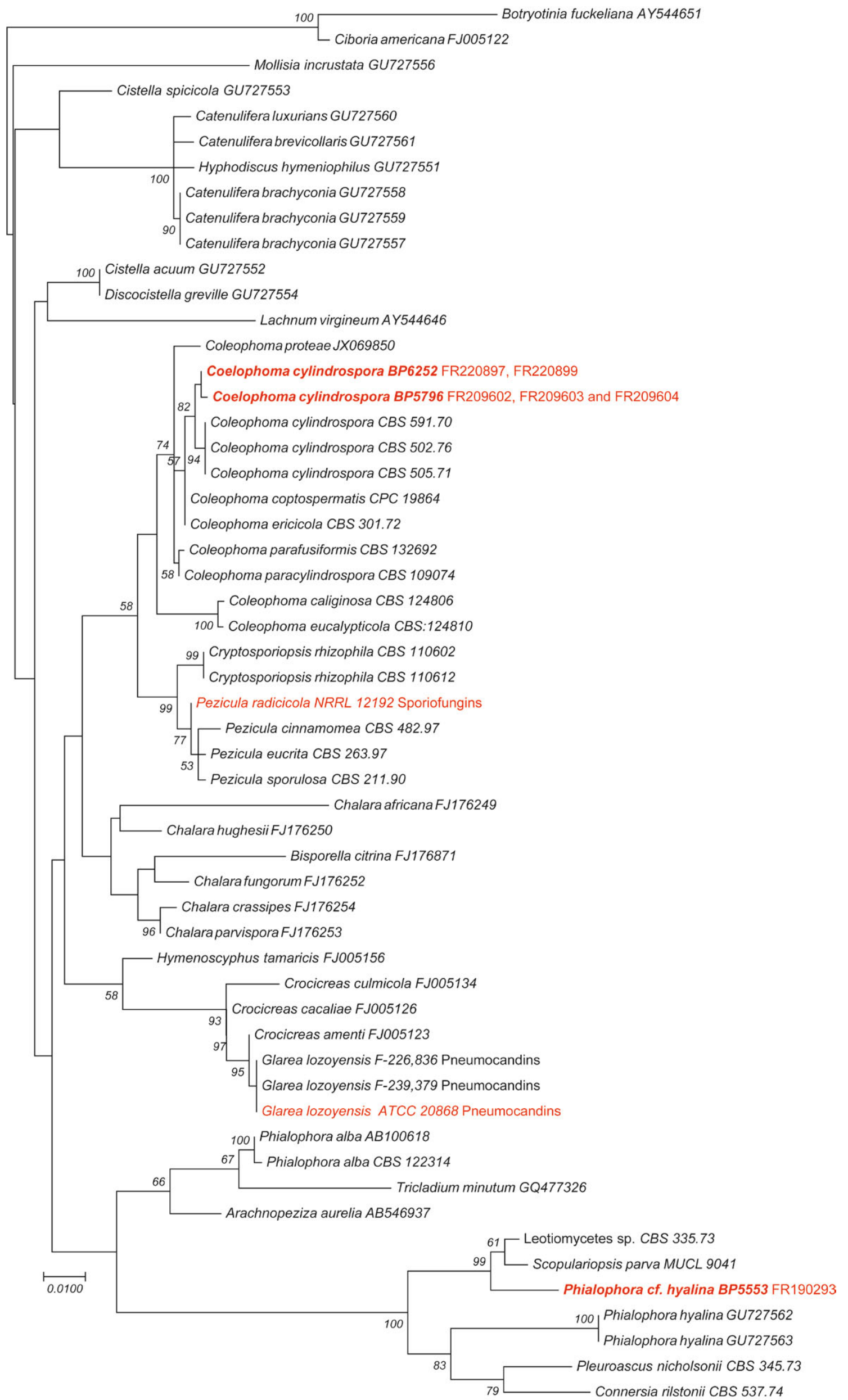




\section{Draft genome sequence of Coleophoma cylindrospora BP5796, the fungus used to produce the echinocandin variants FR209602 and related echinocandins}

\section{INTRODUCTION}

Researchers at Fujisawa Pharmaceuticals (now Astellas Pharma) isolated strain BP5796 (Fujisawa No. 738) from an unidentified leaf sample collected in Japan and identified it as C. crateriformis based on comparisons in conidia dimensions with respect to the known Coleophoma species at the time ( $\mathrm{Wu}$ et al. 1996). The strain was fermented to produce three watersoluble echinocandin analogues, designated FR209602, FR209603 and FR209604 (Fig. 2). These analogues differ from FR901379 (WF11899A) and its analogues by a substitution of threonine for serine at the peptide's third amino acid and deoxygenation of the homotyrosine residue at $\mathrm{C}-4$. Like other echinocandins, these metabolites strongly inhibited activity of $\beta$-1,3-glucan synthase and exhibited potent in vivo activity against $C$. albicans and $A$. fumigatus in murine systemic infection models.

The phylogenetic affinity of the strain producing FR209602 and analogues was established with multiple phylogenetic marker sequences (Yue et al. 2015) (Fig. 7). Although, we had retained the original identification of $C$. crateriformis in previous work on the evolution of the echinocandin pathways, a multi-gene phylogeny indicated the strain was conspecific with other strains named as $C$. empetri. Subsequently, during a revision of the polyphyletic genus Coleophoma, it was noted that an authentic strain of $C$. crateriformis, the type species of the genus Coleophoma, was lacking, and thus, its phylogenetic affinities within the genus remained to be determined (Crous \& Groenewald 2016). Because strain BP5796 appears to be phylogenetically indistinct from the similar C. cylindrospora, we consider it to be conspecific with the latter (Crous \& Groenewald, 2016).

The primary motivation for sequencing the genome of C. cylindrospora BP5796 was to identify the gene clusterencoding the biosynthesis of FR209602. The genome sequence will be essential for identification of the mechanism of the regiospecific sulfation reaction. The draft genome also has revealed, that like BP6252, the strain harbours an auxiliary copy of $\beta-1,3$-glucan synthase that may function as an echinocandin resistance gene (Yue et al. 2018). This draft genome will expand resources for comparative genomics of species in Dermataceae and endophytic fungi.

\section{SEQUENCED STRAIN}

Japan: Toyama Prefecture: Mount Tateyama, isolated from leaf sample, [no further information] (NBRC-NITE BP5796, Fujisawa No. 738).

\section{NUCLEOTIDE SEQUENCE ACCESSION NUMBER}

The C. cylindrospora isolate BP5796 Whole Genome Shotgun project has been deposited in GenBank under the accession number PDLN00000000.

\section{MATERIALS AND METHODS}

The methods for DNA extraction, sequencing, and genome assembly and annotation were essentially the same as for strain BP6252 above.

\section{RESULTS AND DISCUSSION}

The genome of BP5796 was sequenced to 100 -fold coverage, yielding 45 scaffolds with $\mathrm{N} 50$ of $2.0 \mathrm{Mb}$. The assembled genome size was $40.4 \mathrm{Mb}$, and a total of 13257 genes were predicted. The GC content of this genome is $48.5 \%$. The genome contains 24 core catalytic genes associated with putative secondary metabolite biosynthetic gene clusters. These clusters include 15 PKSs, six NRPSs, two dimethylallyl tryptophan synthases, and one terpene synthase. These genes are distributed among 21 putative gene clusters that also include genes encoding tailoring enzymes, regulators, transporters, and other auxiliary genes. In addition to these gene clusters, seven secondary metabolite gene clusters containing PKS-like or NRPS-like enzyme genes, or other secondary metabolic-related genes were identified by antiSMASH. In addition, a gene cluster containing close orthologues of the pneumocandin gene cluster from Glarea lozoyensis (Yue et al. 2015) was recognized, and predicted to be responsible for the biosynthesis of FR206902. This gene cluster deviated from other echinocandin gene clusters by the loss of a cytochrome P450 gene orthologous to htyF in A. pachycristatus and GLP450-1 in Glarea lozoyensis which

Fig. 7. Maximum Likelihood tree of genome-sequenced strains producing echinocandins (red) and selected strains of the Leotiomycetes (55 strains total) based on an alignment of the ITS and 28S rDNA. Botryotinia fuckeliana was positioned as the outgroup. The tree was inferred by using the maximum likelihood method based on the Kimura 2-parameter model. The tree with the highest log likelihood (-4229.10) is shown. The percentage of trees in which the associated taxa clustered together is labelled on branch nodes. A discrete gamma distribution was used to model evolutionary rate differences among sites $(5$ categories $(+G$, parameter $=0.4881)$ ). Branch lengths were measured in the number of substitutions/site. All positions containing gaps and missing data were eliminated. The dataset included 955 positions. Data were analyzed in MEGA7 (Kumar et al. 2016). 
would account for the absence of the hydroxylation at the homotyrosine C4.

Authors: Q. Yue, Y. Li, L. Chen, X. Zhang, K. Li, J. Sun, X. Liu, Z. An, and G.F Bills *Contact: billsge@vt.edu

IMA Genome-F 9H

\section{Draft genome sequence of Fusarium fracticaudum}

\section{INTRODUCTION}

The genus Fusarium contains numerous well-known socioeconomically important fungi (Nelson et al. 1983). Many of these fungi form part of the Fusarium fujikuroi Species Complex (Geiser et al. 2013) for which various whole genome sequences have been published, e.g. Fusarium fujikuroi (Jeong et al. 2013, Wiemann et al. 2013, Chiara et al. 2015), Fusarium temperatum (Wingfield et al. 2015b) and Fusarium circinatum (Wingfield et al. 2012, van der Nest et al. 2014a). The latter causes pitch canker, which is a devastating disease of pine (Wingfield et al. 2008). Of the five other species found to be associated with $F$. circinatum-like symptoms on pine in Colombia (Herron et al. 2015), the genome of $F$. pininemorale has been sequenced (Wingfield et al. 2017). In this study, we determined the whole genome sequence for $F$. fracticaudum, which was also described by Herron et al. (2015). Like F. pininemorale, this species does not seem to be a pathogen of pine as it could not incite lesions on the stems of pine seedlings in standard pathogenicity assays (Herron et al. 2015).These differences between F. circinatum and these non-pathogenic Fusarium species on Pinus will provide an opportunity for genome comparisons.

The association of $F$. fracticaudum with diseased pines and the genetic basis of biological traits in F. fracticaudum is not yet understood. Availability of various sequenced genomes of species within the FFSC is enabling studies into the biology and evolution of these fungi (Ma et al. 2013, De Vos et al. 2014, Niehaus et al. 2016). Here we determine the genome sequence of $F$. fracticaudum, which will provide an additional resource for comparative genomic studies aimed at understanding the evolution of these fungi and unravelling the molecular basis of their plant interactions.

\section{SEQUENCED STRAIN}

Colombia: Angela Maria, Santa Rosa Risalda, 75³6'21" W 4 49'18" $\mathrm{N}$, isolated from diseased Pinus maximinoi trees (CMWF25245; FCC5385; CBS137234; Herron et al. 2015).

\section{NUCLEOTIDE ACCESSION NUMBER:}

This Whole Genome Shotgun project has been deposited at DDBJ/ENA/GenBank under the accession PDNT00000000. The version described in this paper is version PDNT01000000.

\section{METHODS}

\section{Genome sequence}

The $F$. fracticaudum isolate was grown on $1 / 2$ Potato Dextrose agar (PDA; BD Difco ${ }^{\mathrm{TM}}$ ) at $25^{\circ} \mathrm{C}$ for $7 \mathrm{~d}$. Genomic DNA was extracted from fungal mycelium following the protocol of Möller et al. (1992). Genome sequencing was done with one paired-end (350 bp median insert size) and one mate-pair (5 kb median insert size) library using Illumina HiSeq XTen and Hiseq2000 platforms respectively, at Macrogen (Seoul, Korea). CLC Genomics Workbench v. 8.0.1 (CLCBio, Aarhus Denmark) was used to trim sequences less than $18 \mathrm{bp}$. The quality filtered reads were subjected to de novo assembly in ABySS v. 1.3.7 (Simpson et al. 2009), followed by scaffolding with SSPACE $v$ 2.0 (Boetzer et al. 2011). The gaps within the sequences were closed using Gapfiller v. 1.11 (Boetzer \& Pirovano 2012). To determine the completeness of the genome assembly, BUSCO v2.0.1 (Benchmarking Universal Single Copy Orthologs; Simão et al. 2015) was employed using the sordariomycete dataset. Scaffolds were compared to those of the chromosomes of $F$. fujikuroi (Wiemann et al. 2013) and F. temperatum (Wingfield et al. 2015b) using the LASTZ plugin (Harris 2007) of Geneious v 7.0.4 (Kearse et al. 2012). WebAUGUSTUS (Hoff \& Stanke 2013) was used to predict genes using the Fusarium graminearium model (http://bioinf.uni-greifswald.de/augustus) and the cDNA data from the $F$. circinatum genome (Wingfield et al. 2012) as gene evidences.

\section{Phylogenetic analysis}

Phylogenetic analysis was conducted using partial sequences of the elongation factor $1-\alpha$ (ef1- $\alpha$ ) and betatubulin genes from other species in the Fusarium fujikuroi species complex (Herron et al. 2015), including the genome of $F$. fracticaudum determined here. All gene sequences were aligned using MAFFT (Katoh et al. 2009). A maximum likelihood phylogenetic analysis was carried out in PhyML $v$ 3.1 (Guindon et al. 2010) using the GTR+I+G substitution model with 1000 bootstraps, as determined using jModelTest v 2.1.7 (Darriba et al. 2012).

\section{RESULTS AND DISCUSSION}

The assembled genome of $F$. fracticaudum was $46.29 \mathrm{Mb}$ long with a GC content of $47.6 \%$. The assembly consisted of 50 scaffolds with an N50 value of $4491441 \mathrm{bp}$. WebAUGUSTUS predicted a total of 14729 open reading frames (ORFs) in the assembly. Based on the BUSCO results, the assembly was $98.8 \%$ complete (i.e., complete and single-copy BUSCOs $=97.6 \%$; complete and duplicated BUSCOs = $1.2 \%$; fragmented BUSCOs $=0.9 \%$; missing BUSCOs $=0.3 \%$; number of BUSCOs searched $=3725$ ). The phylogeny inferred using two protein-coding genes also shows the previously reported relationships among the FFSC species included (Fig. 8.) (O'Donnell et al. 2000, Geiser et al. 2005, Herron et al. 2015). The sequences extracted from $F$. fracticaudum also grouped with those of another isolate (CBS 137233) and the original GenBank accessions for the isolate sequenced here. 


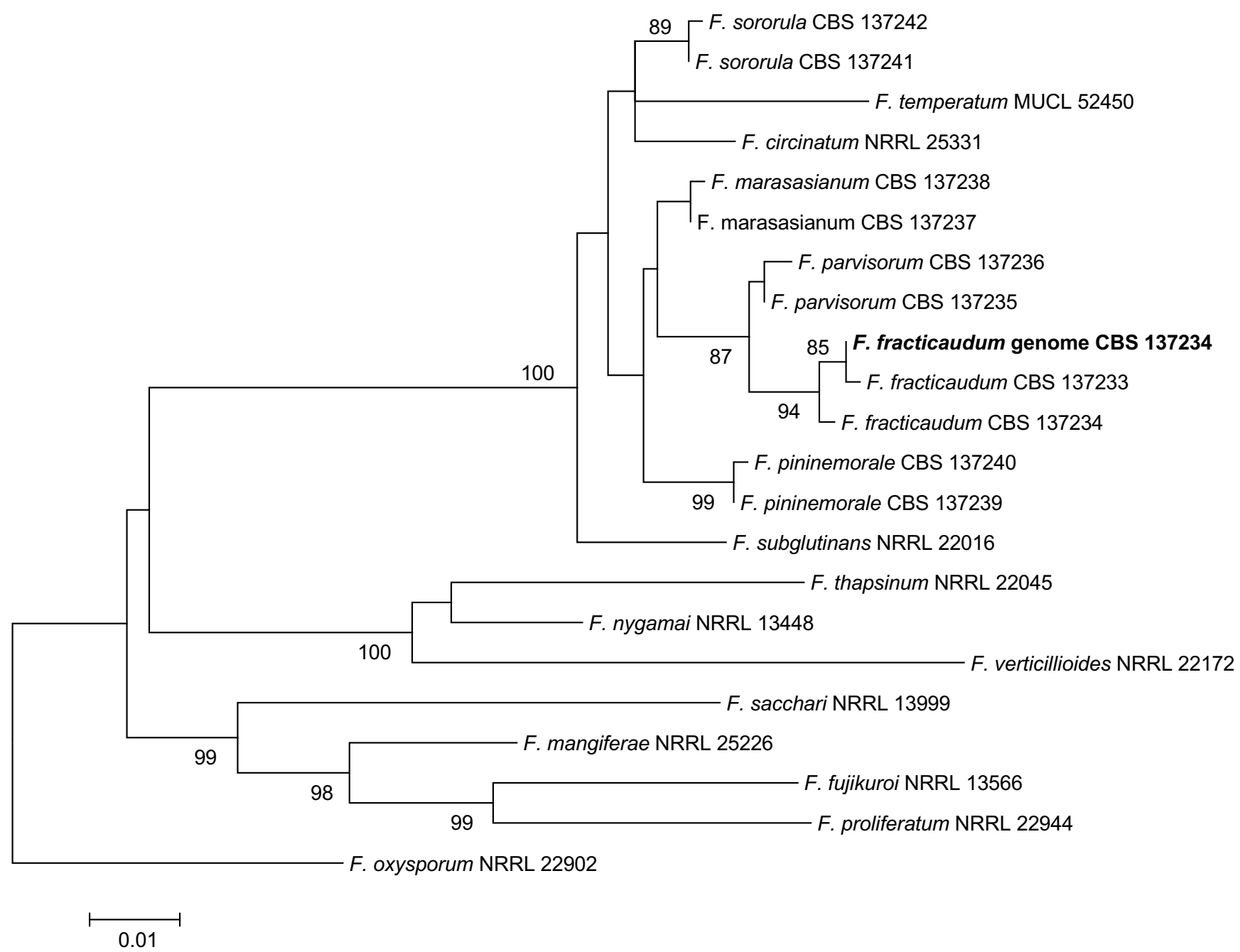

Fig. 8. A Maximum Likelihood phylogeny showing the placement of the F. fracticaudum isolate (indicated in bold) that was sequenced in this study. The tree was inferred from combined $\beta$-tubulin and translation elongation factor 1- $\alpha$ gene sequences (Herron et al. 2015). Values at branch nodes are the bootstrapping confidence values with those $\geq 85 \%$ shown. The scale bar indicates substitution per site.

In terms of overall genome statistics, the whole genome sequence of $F$. fracticaudum is similar to those reported for F. pininemorale, F. circinatum, and F. temperatum (Table 3). Also, $F$. fracticaudum contained the reciprocal translocation between chromosome 8 and 11 known in these fungi (De Vos et al. 2014). However, sequence comparisons showed that chromosome 12, which is dispensable in other members of the FFSC (Xu et al. 1995), is 1094708 bp in size in F. fracticaudum. This is considerably larger than the 692922 bp reported for F. fujikuroi (Wiemann et al. 2013), 986231 bp in F. temperatum (Wingfield et al. 2015b), 791442 bp in F. nygamai (Wingfield et al. 2015a) and 968722 bp reported in F. pininemorale (Wingfield et al. 2017). The differences observed in these genomes highlight the importance of sequencing the genomes of additional species in the FFSC. The $F$. fracticaudum sequenced here, together with those of other FFSC species will undoubtedly provide a platform to answer numerous questions pertaining to the evolutionary history of these fungi and their species-specific traits.

Authors: B.S Swalarsk-Parry*, E.T. Steenkamp, S. van Wyk, T.A Duong, B. D. Wingfield, and L. De Vos *Contact: benny.swalarsk@fabi.up.ac.za

\section{IMA Genome-F 9I}

\section{Draft genome sequence of Phialophora cf. hyalina BP5553, a fungus that produces the sulfated pneumocandin FR190293}

\section{INTRODUCTION}

Researchers at Fujisawa Pharmaceuticals (now Astellas Pharma) isolated strain BP5553 (Fujisawa No. 16616) from soil collected in Japan and identified it as Tolypocladium parasiticum. They fermented the strain to produce the watersoluble echinocandin analogue FR190293 (Fig. 2). Like other echinocandins, FR190293 strongly inhibited $\beta$-1,3glucan synthase and exhibited potent in vitro activity against Candida. albicans and Aspergillus fumigatus. The discovery of this new echinocandin variant was significant because it is the first of the echinocandins to have a dimethyl myristic acid acyl side chain, as in the pneumocandins, in combination with a sulfated homotyrosine residue. 
Table 3. Genome statistics for F. fracticaudum and its close relatives.

\begin{tabular}{lllll}
\hline & F. fracticaudum & F. pininemorale & F. circinatum $^{\mathbf{2}}$ & F. temperatum $^{3}$ \\
\hline \hline Genome size (Mb) & 46.29 & 47.83 & 43.43 & 45.46 \\
GC content (\%) & 47.6 & 46.0 & 47.4 & 47.0 \\
Predicted orfs $^{4}$ & 14729 & 14640 & 15056 & 14284 \\
Average gene length (bp) & 1531 & 1472 & 1312 & 1575 \\
Gene density (ORFs/Mb) & 318 & 306 & 347 & 314 \\
\hline
\end{tabular}

${ }^{1}$ Wingfield et al. (2017); ${ }^{2}$ Wingfield et al. (2012); ${ }^{3}$ Wingfield et al. (2015b); ${ }^{4}$ Open reading frames.

As previously reported, in-depth phylogenetic and morphological analysis of BP5553 demonstrated that the identification as the rotifer parasite $T$. parasiticum (syn. Pochonia parasitica) was erroneous. Rather than belonging to Clavicipitaceae, BP5553 was found to belong in Helotiales (Yue et al. 2015). Based on rDNA and other protein-encoding sequences, BP5553 falls within a monophyletic lineage along with ex-type strains of Phialophora hyalina, Pleuroascus nicholsonii, Scopulariopsis parva, and Scopulariopsis parvula (Fig. 7). These strains, along with other species with Phialophora-like conidial morphs in Helotiales and BP5553 will eventually comprise a new genus in a new family of Helotiales (W. Untereiner et al., unpubl.).

The primary objective behind the sequencing the genome of Phialophora cf. hyalina was the identification of the gene cluster-encoding the biosynthesis of FR190293 (Yue et al. 2015). This draft genome will expand genomic data sets for comparative genomics of species in Leotiomycetes and Helotiales.

\section{SEQUENCED STRAIN}

Japan: Fukushima Prefecture: Iwaki, isolated from soil, [no further information] (NBRC-NITE BP5553, Fujisawa No. 16616).

\section{NUCLEOTIDE SEQUENCE ACCESSION NUMBER}

The Phialophora cf. hyalina isolate BP5553 Whole Genome Shotgun project has been deposited in GenBank under the accession number NPIC00000000.

\section{MATERIALS AND METHODS}

The methods for DNA extraction, sequencing, and genome assembly were essentially the same as for strain BP6252 above.

\section{RESULTS AND DISCUSSION}

The genome of BP5553 was sequenced to 102-fold coverage, yielding 32 scaffolds with $\mathrm{N} 50$ of $3.8 \mathrm{Mb}$. The assembled genome size was $33.6 \mathrm{Mb}$, and a total of 10707 genes were predicted. The GC content of this genome is $48.2 \%$. The genome contains 45 core catalytic genes associated with putative secondary metabolite biosynthetic gene clusters. These clusters include 19 PKSs, 13 NRPSs, six PKS-NRPS hybrids, two dimethylallyl tryptophan synthases, four terpene synthases, and one chalcone synthase. These genes are distributed among 40 putative biosynthetic gene clusters that also include genes encoding tailoring enzymes, regulators, transporters, and other auxiliary genes. In addition to these gene clusters, eight secondary metabolite gene clusters containing PKSlike or NRPS-like enzyme genes, or other secondary metabolic-related genes were identified by antiSMASH. In addition a gene cluster containing close orthologues of the pneumocandin gene cluster from Glarea lozoyensis (Yue et al. 2015) was recognized, and predicted to be responsible for the biosynthesis of FR190293.

Authors: Q. Yue, Y. Li, L. Chen, X. Zhang, K. Li, J. Sun, X. Liu Z. An, and G.F Bills* *Contact: billsge@vt.edu

\section{IMA Genome-F 9J}

\section{Draft genome sequence of Morchella septimelata}

\section{INTRODUCTION}

Morels (Morchella spp., Ascomycota) are a highly desired group of edible fungi with a worldwide distribution (Du et al. 2012, Kanwal et al. 2011, Richard et al. 2015). They have been collected by mycophiles and gourmets for hundreds of years for their delicate taste and unique appearance (Tietel \& Masaphy 2017, 2018, Rotzoll et al. 2006). Morels are also found containing a variety of secondary metabolites with medicinal properties (Tietel \& Masaphy 2018, Shameem et al. 2017, Pfab et al. 2008, Vieira et al. 2016). Morchella septimelata is a black morel, belonging to the Morchella elata clade (Kuo et al. 2012). It was often found in lightly to moderately burned conifer forests, near creek beds, springs and seeps, at an altitude of 1000-2000 m (Pildain et al. 2014). The ascomata of $M$. septimelata can be found primarily in years immediately following forest fires, and then often appearing in dwindling numbers for several seasons 
thereafter (Hobbie et al. 2016). In recent years, artificial cultivation of true morels has made great progress (Masaphy 2010); several Morchella species, such as M. sextelata, $M$. septimelata, and $M$. importuna, have been successfully cultivated in China, America, and other parts of the world. However, the mechanism of the growth and development of Morchella remains unclear, which causes the frequent failure and unstable yield of Morchella cultivation (Liu et al. 2018).

The genome sequence of $M$. septimelata from this study may reveal the mechanism of secondary metabolites synthesis in $M$. septimelata and provide some insights into the growth, development, and carbohydrate degradation of M. septimelata.

\section{SEQUENCED STRAIN}

China: Sichuan: Liangshan Yi, N 27²4' E 10048', alt. 1468 $\mathrm{m}$, isolated from forest soil, 19 Sep. 2015, Chuan Xiong \& Qiang Li (MG91-dried culture).

\section{NUCLEOTIDE SEQUENCE ACCESSION NUMBER}

The Whole Genome Shotgun project $M$. septimelata isolate (Culture collection number SAAS91) has been deposited at $\mathrm{DBJ} / \mathrm{EMBL} /$ GenBank under the accession number PYSJ00000000. The version described in this paper is version PYSJ01000000.

\section{MATERIALS AND METHODS}

Morchella septimelata MG91 was isolated from forest soil in Liangshan Yi Autonomous Prefecture, Sichuan, China, and was preserved in the Fungal Culture Collection Center of Biotechnology and Nuclear Technology Research Institute (Chengdu, Sichuan). Genomic DNA was extracted from MG91 and subjected to sequencing on the Genome Analyzer IIx next-generation sequencing platform (Illumina) at the BGI (Shenzhen, China). Paired-end libraries with respective insert sizes of $425 \mathrm{bp}$ and $725 \mathrm{bp}$ were used to generate read lengths of 150 bases. The CLC Genomics Workbench v. 6.0.1 (CLCBio, Aarhus, Denmark) was subsequently used to trim reads of poor quality (limit of 0.05 ) as well as terminal nucleotides. The remaining reads were assembled using the SPAdes 3.0.0 with an optimized k-mer value of 21 (Bankevich et al. 2012). Thereafter, scaffolding was completed using SSPACE v. 2.0 (Boetzer et al. 2011) and gaps reduced with the use of GapFiller v. 2.2.1 (Boetzer \& Pirovano 2012). The completeness of the assembly was evaluated using the BUSCO v3 (Simão et al. 2015).

Homology-based gene prediction and ab initio prediction were performed to search $M$. septimelata gene models. Homologous protein from Tuber melanosporum was used for alignment to the repeat-masked $M$. septimelata genome using Exonerate v 2.2.0 (Slater \& Birney 2005). The filtered alignment results (above $300 \mathrm{bp}$ and $90 \%$ coverage) were built as training models for $a b$ initio gene prediction. The ab initio prediction was conducted using Augustus v. 3.2.3 (Stanke et al. 2008) and GeneMark-ES (Ter-Hovhannisyan et al. 2008) guided by training models from homology-based alignments. All gene prediction results were integrated into the final gene models by EVidenceModeler (Haas et al. 2008). Carbohydrate-active enzymes (CAZyme), including the repertoire of auxiliary enzymes, were predicted using dbCAN (Yin et al. 2012).

To verify the species identity of the sequenced strain, the Translation Elongation Factor 1-alpha gene for selected Morchella species (Fig. 9.) were aligned with mafft (Katoh \& Standley 2013). The Bayesian inference (BI) method (Erixon et al. 2003) was used to construct the phylogenetic tree of different Morchella species. JMODELTEST 2.0.2 was used to ascertain the best-fit model for nucleotide substitutions (Darriba et al. 2012). BI analysis was performed with MrBayes v3.2.6 (Ronquist et al. 2012). Two independent runs with four chains (three heated and one cold) each were conducted simultaneously for $2 \times 10^{6}$ generations. Each run was sampled every 100 generations. We assumed that stationarity had been reached when estimated sample size (ESS) was greater than 100 , and the potential scale reduction factor (PSRF) approached 1.0. The first $25 \%$ samples were discarded as burn-in, and the remaining trees were used to calculate Bayesian posterior probabilities (BPP) in a $50 \%$ majority-rule consensus tree.

\section{RESULTS AND DISCUSSION}

The genome of $M$. septimelata had an estimated size of 49.81 $\mathrm{Mb}$ with an average coverage of 151.17 times (Table 4). The Scaffold N50 size was 37734 bases, and the assembly had a mean GC content of $47.40 \%$. The total number of scaffold generated was 6525 . A total of 11427 genes were predicted with an average length of $1571 \mathrm{bp}$. A phylogenetic analysis of the genus Morchella is provided to show position of $M$. septimelata (Fig. 9).

The draft genome of $M$. septimelata is larger than that of the closely related species, $M$. conica CCBAS932 (JGI: 1023999) and M. importuna SCYDJ1-A1 (JGI: 1047732), which are $48.21 \mathrm{Mb}$ and $48.80 \mathrm{Mb}$, respectively. Less gene models are found in $M$. septimelata compared to that of these closely related species, $M$. conica CCBAS932 (11 600 gene models) and M. importuna SCYDJ1-A1 (11971 gene models). The average gene length of $M$. septimelata is also smaller than that of $M$. conica CCBAS932 (1668 bp) and $M$. importuna SCYDJ1-A1 (1625 bp). The average gene density of $M$. septimelata was 229 genes/Mb, which is smaller than that of $M$. conica CCBAS932 (240 genes/Mb) and $M$. importuna SCYDJ1-A1 (245 genes/Mb).

A total 512 CAZymes were identified in the genome of $M$. septimelata, which is more than that of the closely related species, M. conica CCBAS932 (401 CAZymes) and $M$. importuna SCYDJ1-A1 (403 CAZymes), indicating that the carbohydrate degradation ability of $M$. septimelata may be stronger than that of the other two closely related species. A total of 9 secondary metabolite (sM) clusters were found in the $M$. septimelata genome, of which $3 \mathrm{sM}$ clusters were for terpenes. The genome sequence data of $M$. septimelata 


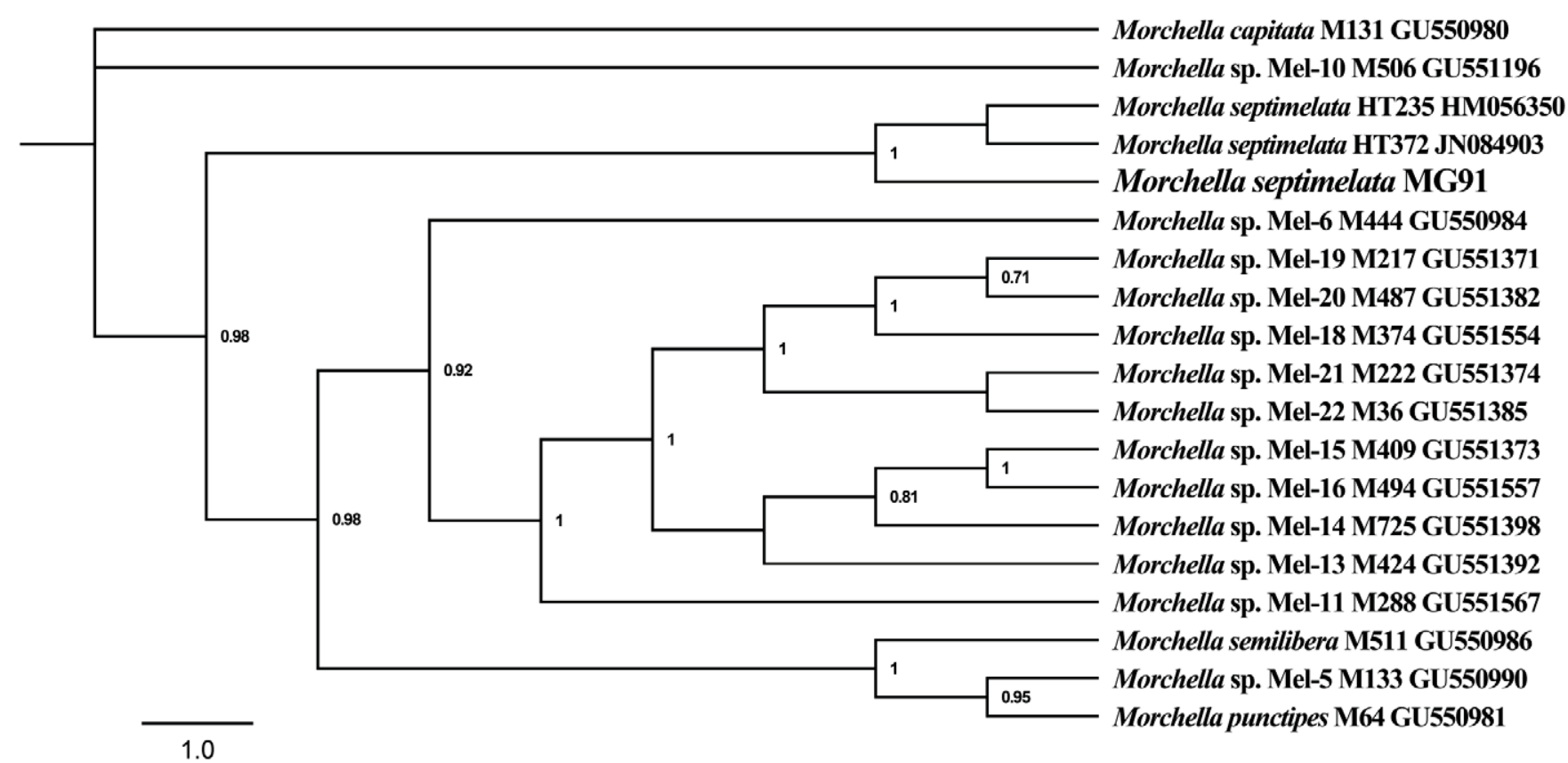

Fig. 9. A Bayesian inference (BI) phylogenetic analysis of genus Morchella using MrBayes v3.2.6 based on partial gene sequences of elongation factor 1-alpha (EF1- $\alpha$ ) gene. Posterior probabilities are shown on the nodes of the tree. The Morchella septimelata isolate used for verification was extracted from the assembled genomes. Reference sequences are obtained from the NCBI database with accession number.

Table 4. Genome statistics, CAZYme richness and secondary metabolite clusters for the Morchella septimelata MG91 genome sequence.

\begin{tabular}{ll}
\hline Genome & M. septimelata \\
& MG91 \\
\hline Coverage & $151.17 x$ \\
BUSCO & $97.7 \%$ \\
Total sequence length (Mb) & 49.81 \\
Scaffolds & 6525 \\
Scaffold N50 (bp) & 37734 \\
GC (\%) & 47.40 \\
Predicted gene models & 11427 \\
Average gene length (bp) & 1571 \\
Average gene density (genes/Mb) & 229 \\
\hline Predicted CAZYmes & \\
Total CAZYmes & 512 \\
Auxiliary activities & 75 \\
Pectate lyases & 23 \\
Glycosyl transferases & 75 \\
Glycoside hydrolases & 201 \\
Carbohydrate esterases & 72 \\
Carbohydrate binding motifs & 66 \\
\hline Predicted secondary Metabolite (sM) & \\
Clusters & \\
Total SM clusters & 9 \\
Terpene clusters & 3 \\
Type I polyketide synthetases (PKSs) & 1 \\
Nonribosomal peptide synthetases (NRPSs) \\
Others & 1 \\
\hline
\end{tabular}

presented in this study will provide useful information for understanding the synthesis mechanism of secondary metabolites in $M$. septimelata and lay a foundation for the artificial cultivation of $M$. septimelata.

\section{Authors: Q. Li, C. Xiong, X. Ma, H. Li, Y. Gao, Y. Dong*, and W. Huang* *Contact: loyalyang@163.com; wenlih11@126.com}

\section{ACKNOWLEDGEMENTS}

The authors of the research on the Berkeleyomyces basicola, Ceratocystis smalleyi, and Fusarium fracticaudum genomes thank the University of Pretoria, the Tree Protection Co-operative Programme (TPCP), the DST-NRF Centre of Excellence in Tree Health Biotechnology, the National Research Foundation, the Genomics Research Institute (GRI) and the DST-NRF SARCHI chair on Fungal Genomics for their financial support.

The research on Cercospora beticola was supported by the United States Department of Agriculture, National Institute of Food and Agriculture Hatch project NYG-625424, and the Director's Controlled Endowment Fund of The New York Agricultural Experiment Station, Cornell University, Geneva, New York, USA.

The research on the genomes of Coleophoma cylindrospora, Phialophora cf. hyalina, and Aspergillus mulundensis was supported by the National Natural Science Foundation of China (NSFC) grants 31629001 to Z.A., 31741004 to Q.Y., Welch Foundation Grant AU0042-20030616 to ZA, and the Kay and Ben Fortson Endowment to GFB. 


\section{REFERENCES}

Afgan E, Baker D, Van den Beek M, Blankenberg D, Bouvier D, et al. (2016) The Galaxy platform for accessible, reproducible and collaborative biomedical analyses: 2016 update. Nucleic Acids Research 44: W3-W10.

Al Adawi AO, Barnes I, Khan IA, AI Subhi AM, Al Jahwari AA, et al. (2013) Ceratocystis manginecans associated with a serious wilt disease of two native legume trees in Oman and Pakistan. Australasian Plant Pathology 42: 179-193.

Albu S, Sharma S, Bluhm BH, Price PP, Schneider RW, et al. (2017) Draft genome sequence of Cercospora cf. sigesbeckiae, a causal agent of Cercospora leaf blight on soybean. Genome Announcements 5: e00708-17.

Al-Subhi AM, Al-Adawi AO, Van Wyk M, Deadman ML, Wingfield MJ (2006) Ceratocystis omanensis, a new species from diseased mango trees in Oman. Mycological Research 110: 237-245.

Bankevich A, Nurk S, Antipov D, Gurevich AA, Dvorkin M, et al. (2012) SPAdes: a new genome assembly algorithm and its applications to single-cell sequencing. Journal of Computational Biology 19: 455-477.

Berkeley MJ, Broome CE (1850) Notices of British fungi. Annals and Magazine of Natural History, ser. 2 5: 455-465.

Bills GF, Yue Q, Chen L, Li Y, An Z, et al. (2016) Aspergillus mulundensis sp. nov., a new species for the fungus producing the antifungal echinocandin lipopeptides, mulundocandins. Journal of Antibiotics 69: 141-148.

Boetzer M, Henkel CV, Jansen HJ, Butler D, Pirovano W (2011) Scaffolding pre-assembled contigs using SSPACE. Bioinformatics 27: 578-579.

Boetzer M, Pirovano W (2012) Toward almost closed genomes with GapFiller. Genome Biology 13: R56.

Bolger AM, Lohse M, Usadel B (2014) Trimmomatic: a flexible trimmer for Illumina sequence data. Bioinformatics 30: 2114-2120.

Cantarel BL, Korf I, Robb SM, Parra G, Ross E, et al. (2008) MAKER: an easy-to-use annotation pipeline designed for emerging model organism genomes. Genome Research 18: 188-196.

Chand R, Pal C, Singh V, Kumar M, Singh VK, et al. (2015) Draft genome sequence of Cercospora canescens: a leaf spot causing pathogen. Current Science 109: 2103.

Chen AJ, Frisvad JC, Sun BD, Varga J, Kocsubé S, et al. (2016) Aspergillus section Nidulantes (formerly Emericella): Polyphasic taxonomy, chemistry and biology. Studies in Mycology 84: 1-118.

Chiara M, Fanelli F, Mule G, Logrieco AF, Pesole G, et al. (2015) Genome sequencing of multiple isolates highlights subtelomeric genomic diversity within Fusarium fujikuroi. Genome Biology and Evolution 7: 3062-3069.

Crous, PW, Groenewald, JZ (2016) They seldom occur alone. Fungal Biology 120: 1392-1415.

Darriba D, Taboada GL, Doallo R, Posada D (2012) jModelTest 2: more models, new heuristics and parallel computing. Nature Methods 9: 772.

Daub ME, Ehrenshaft M (2000) The photoactivated Cercospora toxin cercosporin: contributions to plant disease and fundamental biology. Annual Review of Phytopathology 38: 461-490.

De Beer ZW, Duong TA, Barnes I, Wingfield BD, Wingfield MJ (2014) Redefining Ceratocystis and allied genera. Studies in Mycology 79: 187-219.

De Beer ZW, Marincowitz S, Duong TA, Wingfield MJ (2017) Bretziella, a new genus to accommodate the oak wilt fungus, Ceratocystis fagacearum (Microascales, Ascomycota). MycoKeys 27: 1-19.

De Vos L, Steenkamp ET, Martin SH, Santana QC, Fourie G, et al. (2014) Genome-wide macrosynteny among Fusarium species in the Gibberella fujikuroi complex revealed by amplified fragment length polymorphisms. PLOS ONE 9: e114682.

Deng Y, van Peer AF, Lan FS, Wang QF, Jiang Y, et al. (2016) Morphological and molecular analysis identifies the associated fungus ("Xianghui") of the medicinal white jelly mushroom, Tremella fuciformis, as Annulohypoxylon stygium. International Journal of Medicinal Mushrooms 18: 253-60.

Du XH, Zhao Q, O'Donnell K, Rooney AP, Yang ZL (2012) Multigene molecular phylogenetics reveals true morels (Morchella) are especially species-rich in China. Fungal Genetics and Biology 49: 455-469.

Duong TA, De Beer ZW, Wingfield BD, Wingfield MJ (2013) Characterization of the mating-type genes in Leptographium procerum and Leptographium profanum. Fungal Biology 117: 411-421.

Edgar RC (2004) MUSCLE: multiple sequence alignment with high accuracy and high throughput. Nucleic Acids Research 32: 1792-1797.

Engelbrecht CJ, Harrington TC, Alfenas A (2007) Ceratocystis wilt of cacao - a disease of increasing importance. Phytopathology 97: 1648-1649.

Engelbrecht CJB, Harrington TC (2005) Intersterility, morphology and taxonomy of Ceratocystis fimbriata on sweet potato, cacao and sycamore. Mycologia 97: 57-69.

English AC, Richards S, Han Y, Wang M, Vee V et al. (2012) Mind the gap: upgrading genomes with Pacific Biosciences RL long-read sequencing technology. PLOS ONE 7: e47768.

Erixon P, Svennblad B, Britton T, Oxelman B (2003) Reliability of Bayesian posterior probabilities and bootstrap frequencies in phylogenetics. Systematic Biology 52: 665-673.

Floudas D, Binder M, Riley R, Barry K, Blanchette RA, et al. (2012) The Paleozoic origin of enzymatic lignin decomposition reconstructed from 31 fungal genomes. Science 336: 1715-1719.

Fourie A, Wingfield MJ, Wingfield BD, Barnes I (2014) Molecular markers delimit cryptic species in the Ceratocystis fimbriata sensu lato complex. Mycological Progress 14: 1-18.

Franc GD (2010) Ecology and epidemiology of Cercospora beticola. In: Cercospora Leaf Spot of Sugar Beet and Related Species (RT Lartey, JJ Weiland, L Panella, PW Crous \& CE Windels, eds): 7-19. St Paul, MN: Americal Phytopathological Society Press.

Geiser DM, Aoki T, Bacon CW, Baker SE, Bhattacharyya MK, et al. (2013) One fungus, one name: defining the genus Fusarium in a scientifically robust way that preserves longstanding use. Phytopathology 103: 400-408.

Geiser DM, Ivey ML, Hakiza G, Juba JH, Miller SA (2005) Gibberella xylarioides (anamorph: Fusarium xylarioides), a causative agent of coffee wilt disease in Africa, is a previously unrecognized member of the G. fujikuroi species complex. Mycologia 97: 191-201.

Groenewald JZ, Nakashima C, Nishikawa J, Shin HD, Park JH, et al. (2013) Species concepts in Cercospora: spotting the weeds among the roses. Studies in Mycology 75: 115-170.

Guindon S, Dufayard JF, Lefort V, Anisimova M, Hordijk W, et al. (2010) New algorithms and methods to estimate maximumlikelihood phylogenies: assessing the performance of PhyML 3.0. Systematic Biology 59: 307-321.

Haas BJ, Salzberg SL, Zhu W, Pertea M, Allen JE, et al. Automated eukaryotic gene structure annotation using EVidenceModeler and 
the program to assemble spliced alignments. Genome Biology 11: R7.

Halsted BD, Fairchild DG (1891) Sweet potato black rot. Journal of Mycology 7: 1-11.

Harrington TC (2009) The genus Ceratocystis. Where does the oak wilt fungus fit? In: Proceedings of the 2nd national Oak Wilt symposium (Appel DN, et al. eds): 1-16. Austin, TX: USDA Forest Service, Forest Health Protection,.

Harrington TC, Kazmi MR, Al-Sadi AM, Ismail SI (2014) Intraspecific and intragenomic variability of ITS rDNA sequences reveals taxonomic problems in Ceratocystis fimbriata sensu stricto. Mycologia 106: 224-242.

Harris RS (2007) Improved Pairwise Alignment of Genomic DNA. Ph thesis, Pennsylvania State University, Department of Computer Science and Engineering.

Hawser S, Borgonovi M, Markus A, Isert D (1999) Mulundocandin, an echinocandin-like lipopeptide antifungal agent: biological activities in vitro. Journal of Antibiotics 52: 305-310.

Herron DA, Wingfield MJ, Wingfield BD, Rodas CA, Marincowitz S, et al. (2015) Novel taxa in the Fusarium fujikuroi species complex from Pinus spp. Studies in Mycology 80: 131-150.

Hino M, Fujie A, Iwamoto T, Hori $Y$, Hashimoto $M$, et al. (2001) Chemical diversity in lipopeptide antifungal antibiotics. Journal of Industrial Microbiology and Biotechnology 27: 157-162.

Hobbie EA, Rice SF, Weber NS, Smith JE (2016) Isotopic evidence indicates saprotrophy in post-fire Morchella in Oregon and Alaska. Mycologia 108: 638-645.

Hoff KJ, Stanke M (2013) WebAUGUSTUS - a web service for training AUGUSTUS and predicting genes in eukaryotes. Nucleic Acids Research 41: 123-128.

Ho, Y, Takase S, Tsurumi Y, Hashimoto M, Hino M (2004) WF14573 or its salt, production thereof and use thereof. US Patent 6 730-776. Hsieh HM, Ju YM, Rogers JD (2005) Molecular phylogeny of Hypoxylon and closely related genera. Mycologia 97: 844-865.

Huang Q, Wang YY, Zhao YY, Jiao YX, Li XF, et al. (2008) First report of taro black rot caused by Ceratocystis fimbriata in China. Plant Pathology 57: 780-780.

Iwamoto T, Fujie A, Nitta K, Hashimoto S, Okuhara M, et al. (1994a) WF11899A, B and C, novel antifungal lipopeptides - II. Biological properties. Journal of Antibiotics 47: 1092-1097.

Iwamoto T, Fujie A, Sakamoto K, Tsurumi Y, Shigematsu N, et al. (1994b) WF11899A, B and C, novel antifungal lipopeptides - I. taxonomy, fermentation, isolation and physico-chemical properties. Journal of Antibiotics 47: 1084-1091.

Jeong H, Lee S, Choi GJ, Lee T, Yun S-H (2013) Draft genome sequence of Fusarium fujikuroi B14, the causal agent of the bakanae disease of rice. Genome Announcements 1: e0003500013.

Johnson J (1916) Host plants of Thielavia basicola. Journal of Agricultural Research 7: 289-300.

Johnson JA, Harrington TC, Engelbrecht CJB (2005) Phylogeny and taxonomy of the North American clade of the Ceratocystis fimbriata complex. Mycologia 97: 1067-1092.

Juzwik J, Park J-H, Haugen L (2010) Hickory decline and mortality: update on hickory decline research. In: lowa's Forest Health Report 2010 (Feeley T, ed.): 53-58. Des Moines, IA.

Kanasaki R, Abe F, Kobayashi M, Katsuoka M, Hashimoto M, et al. (2006) FR220897 and FR220899, Novel antifungal lipopeptides from Coleophoma empetri No. 14573. Journal of Antibiotics 59: 149-157.
Kanwal HK, Acharya K, Ramesh G, Reddy MS (2011) Molecular characterization of Morchella species from the Western Himalayan region of India. Current Microbiology 62: 1245-1252.

Katoh K, Asimenos G, Toh H (2009) Multiple alignment of DNA sequences with MAFFT. Methods in Molecular Biology 537: 39-64.

Katoh K, Standley D (2013) MAFFT multiple seqeunce alignment software version 7: Improvements in performance and usablility. Molecular Biology and Evolution 30: 772-780.

Kearse M, Moir R, Wilson A, Stones--Havas S, Cheung M, et al. (2012) Geneious Basic: a integrated and extendable desktop software platform for the organization and analysis of sequence data. Bioinformatics 28: 1647-1649.

Keller O, Kollmar M, Stanke M, Waack S (2011) A novel hybrid gene prediction method employing protein multiple sequence alignments. Bioinformatics 27: 757-763.

Korf I (2004) Gene finding in novel genomes. BMC Bioinformatics 5: 59.

Kumar S, Stecher G, Tamura K (2016) MEGA7: Molecular evolutionary genetics analysis version 7.0 for bigger datasets. Molecular Biology and Evolution 33: 1870-1874.

Kuo M, Dewsbury DR, O'Donnell K, Carter MC, Rehner SA, et al. (2012) Taxonomic revision of true morels (Morchella) in Canada and the United States. Mycologia 104: 1159-1177.

Lal B, Gund VG, Bhise NB, Gangopadhyay AK (2004) Mannich reaction: an approach for the synthesis of water soluble mulundocandin analogues. Bioorganic and Medicinal Chemistry 12: 1751-1768.

Lal B, Gund VG, Gangopadhyay AK, Nadkarni SR, Dikshit DK, et al. (2003) Semisynthetic modifications of hemiaminal function at ornithine unit of mulundocandin, towards chemical stability and antifungal activity. Bioorganic and Medicinal Chemistry 11: 5189-5198.

Lee D-H, Roux J, Wingfield BD, Barnes I, Mostert L, et al. (2016) The genetic landscape of Ceratocystis albifundus populations in South Africa reveals a recent fungal introduction event. Fungal Biology 120: 690-700.

Li H, Lee HS, Kim SH, Moon B, Lee C (2014) Antioxidant and anti-inflammatory activities of methanol extracts of Tremella fuciformis and its major phenolic acids. Journal of Food Science 79: C460-468.

Li Q, Harrington TC, McNew D, Li J, Huang Q, et al. (2016) Genetic bottlenecks for two populations of Ceratocystis fimbriata on sweet potato and pomegranate in China. Plant Disease 100: 2266-2274.

Liu Q, Ma H, Zhang Y, Dong C (2018) Artificial cultivation of true morels: current state, issues and perspectives. Critical Reviews in Biotechnology 38:259-271.

Ma LJ, Geiser DM, Proctor RH, Rooney AP, O'Donnell K, et al. (2013) Fusarium pathogenomics. Annual Review of Microbiology 67: 399-416.

Marçais G, Kingsford C (2011) A fast, lock-free approach for efficient parallel counting of occurrences of k-mers. Bioinformatics 27: 764-770.

Masaphy S (2010) Biotechnology of morel mushrooms: successful fruiting body formation and development in a soilless system. Biotechnology Letters 32: 1523-1527.

Molano EPL, Cabrera OG, Jose J, do Nascimento LC, Carazzolle MF, et al. (2018) Ceratocystis cacaofunesta genome analysis reveals a large expansion of extracellular phosphatidylinositol- 
specific phospholipase-C genes (PI-PLC). BMC Genomics 19: 58.

Mondo SJ, Dannebaum RO, Kuo RC, Louie KB, Bewick AJ, et al. (2017) Widespread adenine N6-methylation of active genes in fungi. Nature Genetics 49: 964-968.

Mukhopadhyay T, Ganguli BN, Fehlhaber HW, Kogler H, Vertesy L (1987) Mulundocandin, a new lipopeptide antibiotic. II. Structure elucidation. Journal of Antibiotics 40: 281-289.

Mukhopadhyay T, Roy K, Bhat RG, Sawant SN, Blumbach J, et al. (1992) Deoxymulundocandin - A new echinocandin type antifungal antibiotic. Journal of Antibiotics 45: 618-623.

Nehl DB, Allen SJ, Mondal AH, Lonergan PA (2004) Black root rot: a pandemic in Australian cotton. Australasian Plant Pathology 33: 87-95.

Nel WJ, Duong TA, Wingfield MJ, Wingfield BD, De Beer ZW (2017) A new genus and species for the globally important, multi-host root pathogen Thielaviopsis basicola. Plant Pathology: DOI 10.1111/ppa.12803.

Nelson PE, Toussoun TA, Marasas WFO (1983) Fusarium Species: an illustrated manual for identification. University Park, PA: Pennsylvania State University Press.

Niehaus E-M, Münsterkötter M, Proctor RH, Brown DW, Sharon A, et al. (2016) Comparative "omics" of the Fusarium fujikuroi species complex highlights differences in genetic potential and metabolite synthesis. Genome Biology and Evolution 8: 3574-3599.

O'Donnell K, Nirenberg HI, Aoki T, Cigelnik E (2000) A multigene phylogeny of the Gibberella fujikuroi species complex: detection of additional phylogenetically distinct species. Mycoscience 41: 61-78.

Park JH, Juzwik J, Cavender-Bares J (2013) Multiple Ceratocystis smalleyi infections associated with reduced stem water transport in bitternut hickory. Phytopathology 103: 565-574.

Park JH, Juzwik J, Haugen LM (2010) Ceratocystis canker of bitternut hickory caused by Ceratocystis smalleyi in the north-central and northeastern United States. Plant Disease 94: 277.

Pereg LL (2013) Black root rot of cotton in Australia: the host, the pathogen and disease management. Crop and Pasture Science 64: 1112-1126.

Pethybridge SJ, Vaghefi N, Kikkert JR (2017) Management of Cercospora leaf spot in conventional and organic table beet production. Plant Disease 101: 1642-1651.

Pfab R, Haberl B, Kleber J, Zilker T (2008) Cerebellar effects after consumption of edible morels (Morchella conica, Morchella esculenta). Clinical Toxicology 46: 259-260.

Pildain MB, Visnovsky SB, Barroetavena C (2014) Phylogenetic diversity of true morels (Morchella), the main edible non-timber product from native Patagonian forests of Argentina. Fungal Biology 118: 755-763.

Piveta G, Ferreira MA, Fb Muniz M, Valdetaro D, ValdebenitoSanhueza R, et al. (2016) Ceratocystis fimbriata on kiwi fruit (Actinidia spp.) in Brazil. New Zealand Journal of Crop and Horticultural Science 44: 13-24.

Polashock, JJ, Caruso, FL, Oudemans, PV, McManus, PS, Crouch, JA (2009) The North American cranberry fruit rot fungal community: a systematic overview using morphological and phylogenetic affinities. Plant Pathology 58: 1116-1127.

Richard F, Bellanger JM, Clowez P, Hansen K, O'Donnell K, et al. (2015) True morels (Morchella, Pezizales) of Europe and North America: evolutionary relationships inferred from multilocus data and a unified taxonomy. Mycologia 107: 359-382.
Ronquist F, Huelsenbeck JP (2003) MrBayes 3: Bayesian phylogenetic inference under mixed models. Bioinformatics 19: 1572 1574.

Ronquist F, Teslenko M, Van der Mark P, Ayres DL, Darling A, et al. (2012) MrBayes 3.2: efficient Bayesian phylogenetic inference and model choice across a large model space. Systematic Biology 61: 539-542.

Rotzoll N, Dunkel A, Hofmann T (2006) Quantitative studies, taste reconstitution, and omission experiments on the key taste compounds in morel mushrooms (Morchella deliciosa Fr.). Journal of Agricultural and Food Chemistry 54: 2705-2711.

Roux J, van Wyk M, Hatting H, Wingfield MJ (2004) Ceratocystis species infecting stem wounds on Eucalyptus grandis in South Africa. Plant Pathology 53: 414-421.

Roy K, Mukhopadhyay T, Reddy GCS, Desikan KR, Ganguli BN. 1987. Mulundocandin, a new lipopeptide antibiotic. I. Taxonomy, fermentation, isolation and characterization. Journal of Antibiotics 40: $275-280$.

Seifert KA, De Beer ZW, Wingfield MJ (2013) The Ophiostomatoid Fungi: expanding frontiers. [CBS Biodiversity Series no. 12.] Utrecht: CBS-KNAW Fungal Biodiversity Centre.

Shameem N, Kamili AN, Ahmad M, Masoodi FA, Parray JA (2017) Antimicrobial activity of crude fractions and morel compounds from wild edible mushrooms of North western Himalaya. Microbial Pathogenesis 105: 356-360.

Simão FA, Waterhouse RM, loannidis P, Kriventseva EV, Zdobnov EM (2015) BUSCO: assessing genome assembly and annotation completeness with single-copy orthologs. Bioinformatics 31: 3210-3212.

Simpson JT, Wong K, Jackman SD, Schein JE, Jones SJ, et al. (2009) ABySS: A parallel assembler for short read sequence data. Genome Research 19: 1117-1123.

Slater GS, Birney E (2005) Automated generation of heuristics for biological sequence comparison. BMC Bioinformatics 6: 31 .

Somasekhara YM (1999) New record of Ceratocystis fimbriata causing wilt of pomegranate in India. Plant Disease 83: 400.

Stamets P (2000) Growth parameters for gourmet and medicinal mushroom species. In: Growing Gourmet and Medicinal Mushrooms (Stamets P, ed.): 402-405. $3^{\text {rd }}$ edn. Berkeley, CA: Ten Speed Press.

Stanke M, Diekhans M, Baertsch R, Haussler D (2008) Using native and syntenically mapped cDNA alignments to improve de novo gene finding. Bioinformatics 24: 637-644.

Stanke M, Steinkamp R, Waack S, Morgenstern B (2004)AUGUSTUS: a web server for gene finding in eukaryotes. Nucleic Acids Research 32: W309-W312.

Stover RH (1950) The black rootrot disease of tobacco: I. Studies on the causal organism Thielaviopsis basicola. Canadian Journal of Research 28: 445-470.

Sutton BC (1980) The Coelomycetes: fungi imperfecti with pycnidia, acervuli and stromata. Kew: Commonwealth Mycological Institute.

Tamura K, Stecher G, Peterson D, Filipski A, Kumar S (2013) MEGA 6: Molecular evolutionary genetics analysis version 6.0. Molecular Biology and Evolution 30: 2725-2729.

Ter-Hovhannisyan V, Lomsadze A, Chernoff YO, Borodovsky M (2008) Gene prediction in novel fungal genomes using an $a b$ initio algorithm with unsupervised training. Genome Research 18: 1979-90.

Tietel Z, Masaphy S (2017) True morels (Morchella) - nutritional and phytochemical composition, health benefits and flavor: a review. 
Critical Reviews in Food Science and Nutrition: DOI:10.1080/10 408398.2017.1285269.

Tietel Z, Masaphy S (2018) Aroma-volatile profile of black morel (Morchella importuna) grown in Israel. Journal of the Science of Food and Agriculture 98: 346-353.

Vaghefi N, Hay FS, Kikkert JR, Pethybridge SJ (2016) Genotypic diversity and resistance to azoxystrobin of Cercospora beticola on processing table beet in New York. Plant Disease 100: 1466-1473.

Vaghefi N, Kikkert JR, Bolton MD, Hanson LE, Secor GA, et al. (2017a) De novo genome assembly of Cercospora beticola for microsatellite marker development and validation. Fungal Ecology 26: 125-134.

Vaghefi N, Kikkert JR, Bolton MD, Hanson LE, Secor GA, et al. (2017b) Global genotype flow in Cercospora beticola populations confirmed through genotyping-by-sequencing. PloS One 12: 0186488.

Van der Nest MA, Beirn LA, Crouch JA, Demers JE, De Beer ZW, et al. (2014a) IMA Genome-F 3: Draft genomes of Amanita jacksonii, Ceratocystis albifundus, Fusarium circinatum, Huntiella omanensis, Leptographium procerum, Rutstroemia sydowiana, and Sclerotinia echinophila. IMA Fungus 5: 472-485.

Van der Nest MA, Bihon W, De Vos L, Naidoo K, Roodt D, et al. (2014b) IMA Genome-F 2: Draft genome sequences of Diplodia sapinea, Ceratocystis manginecans, and Ceratocystis moniliformis. IMA Fungus 5: 135-140.

Van der Nest MA, Steenkamp ET, McTaggart AR, Trollip C, Godlonton T, et al. (2015) Saprophytic and pathogenic fungi in the Ceratocystidaceae differ in their ability to metabolize plantderived sucrose. BMC Evolutionary Biology 15: 1-20.

Van Wyk M, Roux J, Nkuekam GK, Wingfield BD, Wingfield MJ (2012) Ceratocystis eucalypticola sp. nov. from Eucalyptus in South Africa and comparison to global isolates from this tree. IMA Fungus 3: 45-58.

Van Wyk M, Wingfield BD, Clegg PA, Wingfield MJ (2009) Ceratocystis larium sp nov., a new species from Styrax benzoin wounds associated with incense harvesting in Indonesia. Persoonia 22: 75-82.

Vanderpool D, Bracewell RR, McCutcheon JP (2017) Know your farmer: Ancient origins and multiple independent domestications of ambrosia beetle fungal cultivars. Molecular Ecology: DOI:10.1111/mec.14394.

Vieira V, Fernandes A, Barros L, Glamoclija J, Ciric A, et al. (2016) Wild Morchella conica Pers. from different origins: a comparative study of nutritional and bioactive properties. Journal of the Science of Food and Agriculture 96: 90-98.

Walker BJ, Abeel T, Shea T, Priest M, Abouselliel A, et al. (2014) Pilon: An integrated tool for comprehensive microbial variant detection and genome assembly improvement. PLOS ONE 9: e112963.

Weber T, Blin K, Duddela S, Krug D, Kim HU, et al. (2015) AntiSMASH 3.0-a comprehensive resource for the genome mining of biosynthetic gene clusters. Nucleic Acids Research 43: W237243.

Weisenfeld NI, Yin S, Sharpe T, Lau B, Hegarty R, et al. (2014) Comprehensive variation discovery in single human genomes. Nature Genetics 46: 1350-1355.

Wiemann P, Sieber CMK, Von Bargen KW, Studt L, Niehaus E-M, et al. (2013) Deciphering the cryptic genome: genome-wide analyses of the rice pathogen Fusarium fujikuroi reveal complex regulation of secondary metabolism and novel metabolites.
PLOS Pathogens 9: e1003475.

Wilken PM, Steenkamp ET, De Beer ZW, Wingfield MJ, Wingfield BD (2013) IMA Genome-F1: Draft nuclear genome sequence for the plant pathogen, Ceratocystis fimbriata. IMA Fungus 4: 357-358.

Wilken PM, Steenkamp ET, Van der Nest MA, Wingfield MJ, De Beer ZW, et al. (2018) Unexpected placement of the MAT1-1-2 gene in the MAT1-2 idiomorph of Thielaviopsis. Fungal Genetics and Biology 113: 32-41.

Wingfield BD, Ades PK, Al-Naemi FA, Beirn LA, Bihon W, et al. (2015a) IMA Genome-F4. Draft genome sequences of Chrysoporthe austroafricana, Diplodia scrobiculata, Fusarium nygamai, Leptographium lundbergii, Limonomyces culmigenus, Stagonosporopsis tanaceti, and Thielaviopsis punctulata. IMA Fungus 6: 233-248.

Wingfield BD, Ambler JM, Coetzee M, De Beer ZW, Duong TA, et al. (2016a) IMA Genome-F 6: Draft genome sequences of Armillaria fuscipes, Ceratocystiopsis minuta, Ceratocystis adiposa, Endoconidiophora laricicola, E. polonica and Penicillium freii DAOMC 242723. IMA Fungus 7: 217-227.

Wingfield BD, Barnes I, De Beer ZW, De Vos L, Duong TA, et al. (2015b) IMA Genome-F5: Draft genome sequences of Ceratocystis eucalypticola, Chrysoporthe cubensis, C. deuterocubensis, Davidsoniella virescens, Fusarium temperatum, Graphilbum fragrans, Penicillium nordicum, and Thielaviopsis musarum. IMA Fungus 6: 493-506.

Wingfield BD, Berger DK, Steenkamp ET, Lim H, Duong TA, et al. (2017) Draft genome of Cercospora zeina, Fusarium pininemorale, Hawksworthiomyces lignivorus, Huntiella decipiens and Ophiostoma ips. IMA Fungus 8: 385-396.

Wingfield BD, Duong TA, Hammerbacher A, van der Nest MA, Wilson $A$, et al. (2016b) IMA Genome-F7, Draft genome sequences for Ceratocystis fagacearum, C. harringtonii, Grosmannia penicillata, and Huntiella bhutanensis. IMA Fungus 7: 317-323.

Wingfield BD, Steenkamp ET, Santana QC, Coetzee MPA, Bam $S$, et al. (2012) First fungal genome sequence from Africa: a preliminary analysis. South African Journal of Science 108: 1-9.

Wingfield MJ, Hammerbacher A, Ganley RJ, Steenkamp ET, Gordon TR, et al. (2008) Pitch canker caused by Fusarium circinatum - a growing threat to pine plantations and forests worldwide. Australasian Plant Pathology 37: 319-334.

Wu W, Davis RW, Tran-Gyamfi MB, Kuo A, LaButti K, et al. (2017) Characterization of four endophytic fungi as potential consolidated bioprocessing hosts for conversion of lignocellulose into advanced biofuels. Applied Microbiology and Biotechnology 101: 2603-2618.

Wu W, Sutton BC, Gange AC (1996) Coleophoma fusiformis sp. nov. from leaves of Rhododendron, with notes on the genus Coleophoma. Mycological Research 100: 943-947.

Xu JR, Yan K, Dickman MB, Leslie JF (1995) Electrophoretic karyotypes distinguish the biological species of Gibberella fujikuroi (Fusarium section Liseola). Molecular Plant-Microbe Interactions 9: 74-84.

Yin Y, Mao X, Yang JC, Chen X, Mao F, et al. (2012) dbCAN: a web resource for automated carbohydrate-active enzyme annotation, Nucleic Acids Research 40: W445-W451.

Yue Q, Chen, L, Zhang X, Li K, Sun J, Liu X, An Z, Bills GF (2015) Evolution of chemical diversity in echinocandin lipopeptide antifungal metabolites. Eukaryotic Cell 14: 698-718.

Yue Q, Li Y, Chen L, Zhang X, Liu X, An Z, Bills GF (2018) Genomicsdriven discovery of a novel self-resistance mechanism in 
the echinocandin-producing fungus Pezicula radicicola. Environmental Microbiology: in press: DOI.org/10.1111/14622920.14089 .
Zerbino DR, Birney E (2008) Velvet: algorithms for de novo short read assembly using de Bruijn graphs. Genome Research 18 821-829. 